\title{
Acid Ceramidase Deficiency in Mice Leads to Severe Ocular Pathology and Visual Impairment
}

Fabian P.S. Yu, ${ }^{* \dagger}$ Benjamin S. Sajdak, Jakub Sikora, ${ }^{\ddagger}$ Alexander E. Salmon, ${ }^{\dagger}$ Murtaza S. Nagree, ${ }^{\dagger \|}$ Jiři Gurka, ${ }^{* *}$

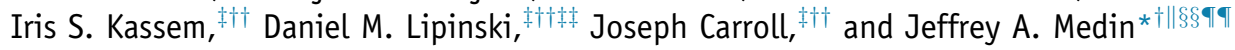

From the Institute of Medical Science* and the Department of Medical Biophysics, "University of Toronto, Toronto, Ontario, Canada; the Departments of Pediatrics, ${ }^{\dagger}$ Cell Biology, Neurobiology and Anatomy, ${ }^{\ddagger}$ Ophthalmology and Visual Sciences, ${ }^{\dagger \dagger}$ and Biochemistry, ${ }^{\S \S}$ Medical College of Wisconsin, Milwaukee, Wisconsin; the Rare Diseases Research Unit, ${ }^{\S}$ Department of Pediatrics and Adolescent Medicine, and the Institute of Pathology, ${ }^{\circledR} 1$ st Faculty of Medicine, Charles University, Prague, Czech Republic; the Department of Cardiology, ** Institute for Clinical and Experimental Medicine, Prague, Czech Republic; the

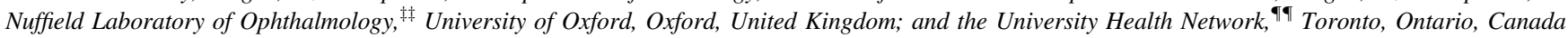

Accepted for publication October 23, 2018.

Address correspondence to Jeffrey A. Medin, Ph.D., Medical College of Wisconsin, 8701 W. Watertown Plank Road, CRI: C4540, Milwaukee, WI 53226. E-mail: jmedin@ mcw.edu.

\begin{abstract}
Farber disease (FD) is a debilitating lysosomal storage disorder characterized by severe inflammation and neurodegeneration. FD is caused by mutations in the ASAH1 gene, resulting in deficient acid ceramidase (ACDase) activity. Patients with ACDase deficiency exhibit a broad clinical spectrum. In classic cases, patients develop hepatosplenomegaly, nervous system involvement, and childhood mortality. Ocular manifestations include decreased vision, a grayish appearance to the retina with a cherry red spot, and nystagmus. That said, the full effect of ACDase deficiency on the visual system has not been studied in detail. We previously developed a mouse model that is orthologous for a known patient mutation in Asah1 that recapitulates human FD. Herein, we report evidence of a severe ocular

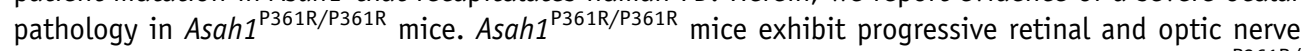
pathology. Through noninvasive ocular imaging and histopathological analyses of these Asah1 $1^{\text {P361R/ }}$ ${ }_{\mathrm{P} 361 \mathrm{R}}$ animals, we revealed progressive inflammation, the presence of retinal dysplasia, and significant storage pathology in various cell types in both the retina and optic nerves. Lipidomic analyses of retinal tissues revealed an abnormal accumulation of ceramides and other sphingolipids. Electroretinograms and behavioral tests showed decreased retinal and visual responses. Taken together, these data suggest that ACDase deficiency leads to sphingolipid imbalance, inflammation, dysmorphic retinal and optic nerve pathology, and severe visual impairment. (Am J Pathol 2019, 189: 320-338; https://doi.org/ 10.1016/j.ajpath.2018.10.018)
\end{abstract}

Farber disease (FD; Online Mendelian Inheritance in Man number 228000) is an autosomal recessive lysosomal storage disorder caused by mutations in the ASAH1 gene, resulting in deficient acid ceramidase (ACDase) activity. ${ }^{1}$ ACDase is a key lysosomal enzyme that hydrolyzes the bioactive lipid ceramide into sphingosine ( $\mathrm{Sph}$ ) and a free fatty acid. ${ }^{2}$ Currently, there is no cure for FD, and with only 152 cases recorded in the literature to date, obtaining tissues and samples to study this disorder has been challenging. ${ }^{3}$ The clinical manifestations of FD are broad; patients with the classic variant die early in childhood. ${ }^{1}$ The cardinal features of FD are the presence of s.c. lipogranulomatous nodules, joint contractures, and aphonia. ${ }^{1}$ Patients with severe forms of FD will also develop respiratory complications, hepatosplenomegaly, and neurologic decline.
Impaired ACDase activity leads to systemic ceramide accumulation in FD patients. Ceramide and other sphingolipids are key components of membranes and play a role in a variety of cellular functions, including inflammation, cell proliferation, and apoptosis. ${ }^{6}$ The balance of ceramide and

\footnotetext{
Supported by the Midwest Athletes Against Childhood Cancer Fund Professorship (J.A.M.). Ocular imaging analyses were supported by $\mathrm{NIH}$ grants P30EY001931 (B.S.S., A.E.S., I.S.K., D.M.L., and J.C.) and T32EY014537 (B.S.S. and A.E.S.). The electron microscopic analyses were supported by Operační program Praha konkurenceschopnost grant CZ.2.16/3.1.00/24509, National Center for Medical Genomics grant LM2015091, the Charles University Institutional Research and Development scheme, and Progres Q26 (J.S.).
}

Disclosures: None declared. 
its metabolites are tightly regulated, and dysregulation results in disease and potential visual system defects. ${ }^{7,8}$

The most frequent ophthalmic manifestation that has been described in patients with FD is a cherry red spot in the macula. ${ }^{3,9-12}$ Other reported ocular phenotypes in patients with FD include corneal opacities, xanthoma-like growths on the conjunctiva, nystagmus, and macular degeneration. ${ }^{13-15}$

Ocular manifestations are a common feature in lysosomal storage disorders in general, and corresponding rodent models of the disorders have been instrumental for characterizing their pathogenesis. ${ }^{16-19}$ We previously reported the first viable model for ACDase deficiency, wherein a known human ASAH1 mutation, proline (P) 362 to arginine (R), was knocked in to the corresponding locus in murine Asahl (P361R) ${ }^{20}$ Mice homozygous for this mutation mirror many FD patient features, including heightened inflammation and pathology in the hematopoietic, respiratory, and neuroglial systems that leads to early mortality. ${ }^{20-22}$

In this study, we investigated the consequences of ACDase deficiency by completing a comprehensive investigation of ocular manifestations in the Asahl $1^{\mathrm{P} 361 \mathrm{R} / \mathrm{P} 361 \mathrm{R}}$ mouse model of FD. Noninvasive ocular imaging was used to monitor disease progression and highlight the abnormal sphingolipids present in the retina. Furthermore, ACDase deficiency was found to reduce visual function that is, in part, due to progressive inflammation, neurologic involvement, and abnormal storage pathology in cells of the visual system.

\section{Materials and Methods}

\section{Animal Use, Breeding, and Genotyping}

To generate homozygous Asahl $1^{\mathrm{P} 361 \mathrm{R} / \mathrm{P} 361 \mathrm{R}}$ mice, Asahl $1^{+/ \mathrm{P} 361 \mathrm{R}}$ heterozygotes were crossed, as previously reported. ${ }^{20}$ Genotypes were confirmed by PCR using genomic DNA isolated from ear notches. To detect the wild-type Asahl allele, the following primers were used: 5'-CAGAAGGTATGCGG CATCGTCATAC- $3^{\prime}$ (forward) and 5'-AGGGCCATACA GAGAAACCCTGTCTC- $3^{\prime}$ (reverse). These primers yielded a 379-bp product. For the Asah1 knock-in allele, the following primers were used: $5^{\prime}$-TCAAGGCTTGACTTTGGGGCAC$3^{\prime}$ (forward) and $5^{\prime}$-GCTGGACGTAAACTCCTCTTCA GACC- $3^{\prime}$ (reverse). These primers amplify a 469-bp product from the neomycin resistance cassette. All animal procedures were approved and performed in strict adherence to the policies of the Medical College of Wisconsin Institutional Animal Care and Use Committee. Animals used for this study were maintained in controlled ambient illumination on a 12-hour light/ dark cycle, with an illumination level of 2 to 3 lux. Exposure to bright light was kept to a minimum for all study animals for the duration of this study.

\section{Slit-Lamp Analysis}

Mice were anesthetized with inhaled isoflurane (3\% induction, $1 \%$ to $2 \%$ maintenance) in $0.6 \mathrm{~L} /$ minute oxygen flow.
The cornea and the lens were evaluated and imaged with the Topcon SL-D81 slit-lamp biomicroscope (Topcon Medical Systems Inc., Oakland, NJ) with a digital camera (Nikon D810 36.3MP DSLR Camera; Nikon Inc., Melville, NY). The eye was then dilated and cyclopleged with one eye drop each of $2.5 \%$ phenylephrine hydrochloride and $1 \%$ tropicamide (Akron, Inc., Lake Forest, IL). The lens was then reevaluated and imaged after dilation. All examinations were performed by a board-certified ophthalmologist (I.S.K.) with experience in animal models of ocular disease.

\section{Fundus Imaging and Confocal Scanning Laser Ophthalmoscopy}

Mice were anesthetized and prepared for imaging as described above. Fundus images were taken with the Phoenix Micron IV (Phoenix Research Labs, Pleasanton, CA). Near-infrared (810-nm) reflectance imaging and blue autofluorescence (excitation, $486 \mathrm{~nm}$; emission filter, 525/50 nm) imaging were performed with a customized Heidelberg Spectralis (Heidelberg Engineering, Heidelberg, Germany) confocal scanning laser ophthalmoscope (cSLO). The automatic realtime composite mode in the Spectralis software version 6.6.2.0 (Heidelberg Engineering, Heidelberg, Germany) was used to average 40 and 100 frames of the near-infrared and blue autofluorescence images, respectively.

\section{Optical Coherence Tomography}

To perform optical coherence tomography (OCT) imaging, mice were anesthetized and prepared for imaging as described above. Imaging was performed with a Bioptigen Envisu R2200 spectral domain-OCT system (Leica Microsystems, Wetzlar, Germany) equipped with a Superlum Broadlighter T870 light source centered at $878.4 \mathrm{~nm}$ with a $186.3-\mathrm{nm}$ bandwidth (Superlum, Cork, Ireland). InVivoVue control software version 2.4.33 (Leica Microsystems, Wetzlar, Germany) and the Bioptigen mouse objective were used for retinal imaging. A customized Bioptigen mouse stage was used to aim the imaging beam to the desired retinal location. GenTeal lubricant eye gel and Systane Ultra lubricating eye drops (Alcon, Fort Worth, TX) were used as needed to maintain corneal hydration. Dispersion, reference arm position, and light power of the sample arm were optimized iteratively for each animal at each time point. During acquisition, all scans were displayed and acquired in logarithmic intensity mode. Horizontal line scans $(1 \mathrm{~mm}, 1000$ A-scans/B-scan; 100 repeated scans) of the retina were acquired with the optic nerve head $(\mathrm{ONH})$ centered for each scan. With our system and these scan parameters, the pixel size was calculated to be $1.00 \times 1.61 \mu \mathrm{m}$ ( $x z$ axes, respectively). B-scans (20 to 50) were registered to a manually selected template frame and averaged using custom software described previously. ${ }^{23}$ The registration was limited to a displacement of approximately $10 \mu \mathrm{m}$ to exclude scans acquired at different retinal locations. The Duke OCT Retinal Analysis Program version 63.6 (Duke 
University, Durham, NC) was used to segment the inner limiting membrane and the retinal pigmented epithelium, ${ }^{24}$ which were clearly visible in all animals. Total retinal thickness was defined as the optical path length between these boundaries, assuming a group refractive index of 1.38. The order of the images was randomized, the boundaries were manually corrected, and thickness was analyzed by an observer (A.E.S.) masked to the genotype.

\section{ERG}

Before testing herein, mice were dark adapted overnight. Apparatus setup and animal preparations were conducted under dim red illumination. Mice were anesthetized and prepared as they were for imaging. Mice were placed on a heated platform $\left(38^{\circ} \mathrm{C}\right)$. A silver-coated nylon contact lens with a custom-made active electrode was positioned on the eye. To maintain electrical conductivity, two subdermal platinum needle electrodes were positioned in the scruff (reference) and base of the leg (ground). Prepared animals were then positioned inside the Ganzfeld dome of the Espion E2 system (Diagnosys LLC, Cambridge, UK). All recordings were completed in a custom-made Faraday cage. Signals from the electroretinogram (ERG) were differentially amplified and digitized at a rate of $5 \mathrm{kHz}$ (bandpass filtered 0 to $100 \mathrm{~Hz}$ ). Recording sessions started with the dark-adapted flash ERG, which consisted of a six-log intensity series $\left(-4\right.$ to $\left.1 \log \mathrm{cd} \cdot \operatorname{second} / \mathrm{m}^{2}\right)$. Twenty responses were collected and averaged for the -4 and $-3 \log$ $\mathrm{cd} \cdot \mathrm{second} / \mathrm{m}^{2}$ stimulus with an interstimulus internal of 5 seconds, 10 responses were collected and averaged for the -2 and $-1 \log \mathrm{cd} \cdot \operatorname{second} / \mathrm{m}^{2}$ stimuli with an interstimulus interval of 10 seconds, and five responses were collected and averaged for the 0 and $1 \log \mathrm{cd} \cdot \mathrm{second} / \mathrm{m}^{2}$ stimuli with an interstimulus interval of 20 seconds. For the light-adapted series, mice were first exposed to a 30 $\mathrm{cd} \cdot$ second $/ \mathrm{m}^{2}$ white light background for 10 minutes for rod saturation, then progressed to a light-adapted flash ERG over a two-log intensity series ( 0 to $1 \log \mathrm{cd} \cdot \operatorname{second} / \mathrm{m}^{2}$ ). Twenty responses were collected and averaged for each condition. Recordings concluded with two flicker ERG tests performed with continuous 5- and $15-\mathrm{Hz}$ flicker (30 $\mathrm{cd} \cdot \operatorname{second} / \mathrm{m}^{2}$ ). Thirty responses were collected and averaged for each flicker condition.

\section{Visual Cliff Behavioral Test}

To evaluate visual perception, a mouse open-field setup was modified to replicate the presence of a visual cliff. ${ }^{25}$ In brief, a gray circular structure with a diameter of $49.5 \mathrm{~cm}$ was placed on top of a clear $60 \times 60-\mathrm{cm}$ plexiglass surface, half of which was hanging off a table. To enhance the edge effect, the portion of the plexiglass surface on the support table was covered with a checkered pattern. Lamps directed at the floor, which also had a checkered pattern, were used to enhance depth and add illumination. Mice were placed near the middle of the visual cliff and monitored for 5 minutes with a camera linked to the Any-Maze behavior tracking software version 3.9.6 (Any-Maze, Stoelting, IL). For data analysis, three zones were created: ground, air, and cliff zones. The cliff zone measured $3 \mathrm{~cm}$ in depth from the edge of both the ground and air side. This 3-cm area was excluded from data collection because normal animals frequently stretched their body over the cliff edge to assess the area. For data collection, total distance traveled and total movement time were used to measure activity. To reduce variability, circadian rhythms were taken into account and all experiments were performed between 7 and 11 AM. All tests were performed on the same apparatus, in the same room, and by the same individual.

\section{Histopathology and Eye Measurements}

For these studies, mice were euthanized via carbon dioxide inhalation and immediately perfused with ice-cold phosphate-buffered saline via cardiac puncture with a 24-gauge needle. Globes were enucleated with the optic nerve intact and fixed in $10 \%$ phosphate-buffered formalin or Davidson's fixative for 24 to 48 hours. Whole-eye globes and separated optic nerves were dehydrated and embedded in paraffin. Globes were sectioned sagittally at the midline through the optic nerve $(\mathrm{ON})$ and stained for hematoxylin and eosin (H\&E) and Luxol fast blue. Histology slides were scanned on the Aperio AT2 histology slide scanner (Leica Biosystems, Buffalo Grove, IL) or NanoZoomer 2.0-HT histology slide scanner (Hamamatsu Photonics, Ichinocho, Japan). All analyses and measurements were performed using Aperio ImageScope analysis software version 12.3.3 (Leica Biosystems, Buffalo Grove, IL). Morphometric analyses of the retinal layers were obtained approximately two- to three-disc diameters away from the optic nerve. Samples that contained retinal folding two- to three-disc diameters from the optic nerve were excluded from measurements. The anterior-to-posterior globe measurements were taken from the midline of the cornea to the base of the retinal epithelium (Bruch membrane). The remainder of the globe, lens, and corneal measurements were obtained at the anterior/posterior or dorsal/ventral midlines.

\section{Retinal Dysplasia Scoring}

H\&E-stained retinal sections from $A_{s a h 1^{+/+}}$and Asah1 ${ }^{\mathrm{P} 361 \mathrm{R} / \mathrm{P} 361 \mathrm{R}}$ mice at 3 to 4 and 8 to 9 weeks of age were evaluated for retinal dysplasia severity. Our retinal dysplasia scoring system contained three categories: normal, intermediate, and severe. Samples categorized as normal contained no overt folding but may have had minor ridges within the retina. The height of each ridge was $\leq 20 \mu \mathrm{m}$, and no more than two retinal layers were affected. Samples in the intermediate category consisted of one to two folds/ whorls. Each fold/whorl affected up to three retinal layers, and the peak height of each fold/whorl was between 20 and 
$100 \mu \mathrm{m}$. Last, for the severe category, samples displayed more than two folds/whorls. The folds/whorls there also affected more than three retinal layers, and the peak height of each fold/whorl was $>100 \mu \mathrm{m}$. Some cases of severe folding also showed signs of retinal detachment.

\section{Immunohistochemistry and Immunofluorescence}

Eyes were fixed in $10 \%$ formalin overnight for retinal sectioning, as described above. For immunohistochemistry (IHC), the following primary antibodies, secondary antibodies, and staining reagents were used: rat anti-mouse Mac2 at 1:8000 (galectin-3 clone M3/38; Cedarlane, Burlington, ON, Canada); goat anti-mouse cathepsin D at 1:3000 (Santa Cruz Biotechnology, Dallas, TX); biotinylated rabbit anti-rat IgG antibody at 1:5000 (Vector Laboratories, Burlingame, CA); biotinylated donkey anti-rabbit IgG antibody at 1:500 (Vector Laboratories); avidin-biotin/horseradish peroxidase (Vector Laboratories); 3,3'-diaminobenzidine kit (Vector Laboratories); and Vectastain ABC Elite Standard kit (Vector Laboratories). For immunofluorescence staining, the following primary antibodies were used: rabbit anti-ionized, calcium-binding adapter molecule 1 (Iba1) at 1:2000 (Wako Chemicals USA, Cambridge, MA) and chicken anti-glial fibrillary acidic protein (GFAP) at 1:2000 (Aves Lab Inc., Tigard, OR). DAPI at 1:7000 (Sigma Aldrich, St. Louis, MO) was used for nuclear staining. The following secondary antibodies were used to detect the primary antibodies: goat antichicken fluorescein isothiocyanate 1:500 (Aves Lab Inc.) and donkey anti-rabbit Cy3 1:500 (Jackson ImmunoResearch USA, West Grove, PA). Immunofluorescence microscopy was performed on the Carl Zeiss LSM510 confocal microscope (Carl Zeiss Microscopy, LLC, Thornwood, NY) using the Zeiss Aim software version 4.2 (Carl Zeiss Microscopy, LLC).

\section{Electron Microscopy}

After euthanasia, mice were perfused with $4 \%$ paraformaldehyde. Eye globes with intact ONs were removed and placed in $4 \%$ paraformaldehyde for 24 to 48 hours. ONs were from the posterior pole of the eye globe; approximately 2-mm transverse sections were cut for transmission electron microscope processing. For analysis of the posterior chamber, the cornea was gently cut to expose and remove the lens. The remaining posterior segment structures were used for transmission electron microscope processing. In brief, samples were post-fixed in 3\% glutaraldehyde, washed, and placed in $2 \% \mathrm{OsO}_{4}$ in phosphate buffer overnight for contrasting. After dehydration, samples were embedded in Durcupan Epon (Fluka, Hatfield, PA) for polymerization. Ultrathin sections (60 $\mathrm{nm}$ thick) were cut from tissue blocks of $\mathrm{ON}$ and posterior eye samples and placed on copper grids. Ultrathin sections were further stained with uranyl acetate and lead citrate. Samples were analyzed with the JEOL 1400+ (JEOL, Tokyo, Japan) transmission electron microscope equipped with an Olympus Veleta charge-coupled device camera (Olympus Soft Imaging Solutions GMBH, Münster Germany) and Radius software version 1.3 (Olympus, Tokyo, Japan).

To assess myelin sheath thickness, the G-ratio (axon diameter/total outer myelin sheath diameter) was measured on electron micrographs of $\mathrm{ON}$ cross sections from 8- to 9week-old mice. Images of the $\mathrm{ON}$ were obtained at a magnification of $\times 2500$ ( $x y$ axes image sampling density, $27.9 \mathrm{~nm}$ ). The G-ratio was determined from 300 to 400 randomly chosen fibers per nerve cross section. Images were analyzed using ImageJ software version $1.51(\mathrm{NIH}$, Bethesda, MD; https://imagej.nih.gov/ij/index.html), and Gratio measurements were performed with the G-ratio plugin and online source code (http://gratio.efil.de, last accessed June 12, 2018).

\section{Sphingolipid Mass Spectrometry}

After mice were euthanized and perfused as described above, globes were enucleated. Retinas were then carefully separated from the globes under a dissection microscope. Retinal tissue was homogenized in $300 \mu \mathrm{L}$ phosphate-buffered saline with the Omni Bead Raptor 24 tissue homogenizer (Omni International, Inc., Kennesaw, GA) using 2.8-mm ceramic beads. Lipids were extracted from $100 \mu \mathrm{L}$ of retinal tissue lysate with $400 \mu \mathrm{L}$ of methanol. The supernatant was reconstituted with $300 \mu \mathrm{L}$ of water for mass spectrometry analyses, as previously described. ${ }^{26}$ The following internal standards were spiked in to each retina homogenate before extraction: $50 \mathrm{ng}$ each of deuterated ceramide-1-phosphate [d18:1/16:0 or d18:1/24:0 (Matreya Inc., Pleasant Gap, PA) and d18:1/24:1 (Avanti Polar Lipids Inc., Alabaster, AL)]; 50 ng of deuterated ceramide (d18:1/22:0; Medical University of South Carolina Lipidomics Core, Charleston, SC); $50 \mathrm{ng}$ of C17 analog of monohexosylceramide (d:18:1/17:0; Avanti Polar Lipids Inc.); $500 \mathrm{ng}$ of $\mathrm{C} 17$ analog of sphingomyelin (d18:1/17:0; Avanti Polar Lipids Inc.); 100 ng of $\mathrm{d}_{7-} \mathrm{Sph}$ (Avanti Polar Lipids Inc.); and $100 \mathrm{ng}$ of $\mathrm{d}_{7-\text { sphingosine-1- }}$ phosphate (S1P; Avanti Polar Lipids Inc.).

The samples were analyzed on the Shimadzu 20AD highperformance liquid chromatography system using reversephase C18 high-performance liquid chromatography columns (Agilent Co, Santa Clara, CA) and a Leap PAL autosampler coupled to a triple quadrupole mass spectrometer (API-4000; Applied Biosystems, Carlsbad, CA) operated in multiple reaction mode at the Medical University of South Carolina Lipidomics Core. Positive-ion electrospray ionization mode was used to detect all sphingolipids. Retinal extraction samples were injected in duplicate for data averaging. The Analyst software version 1.5.1 was used for data analysis (Applied Biosystems). Sphingolipid measurements were normalized for individual protein concentrations obtained via a bicinchoninic acid assay (Thermo Scientific Pierce, Waltham, MA) and expressed as fold-change over results from $\mathrm{Asahl}^{+/+}$mice. 
Lipidomic analyses were conducted separately on retinal tissue from the two different age groups. Ceramide-1phosphate $(\mathrm{C} 1 \mathrm{P})$ was analyzed in retinal samples from 8to 9-week-old mice but could not be analyzed in 3- to 4week-old mice because of insufficient tissue lysate and lipid standards. S1P levels were lower than the limit of detection in retinal samples from both 3- to 4- and 8- to 9week-old mice.

\section{Statistical Analysis}

Data are expressed as means \pm SEM and analyzed with a $t$ test unless otherwise stated. Statistics were performed using GraphPad Prism software version 5.0 (GraphPad Software Inc., La Jolla, CA) and MATLAB (MathWorks, Inc., Natick, MA). $P<0.05$ was considered statistically significant.

\section{Results}

\section{Noninvasive Imaging Reveals Ocular Pathology}

In comparison to control 8- to 9-week-old $\mathrm{Asahl}^{+/+}$mice (Figure 1A), slit-lamp examination of the anterior chamber revealed signs of uveitis in 8- to 9-week-old Asahl $1^{\mathrm{P} 361 \mathrm{R} / \mathrm{P} 361 \mathrm{R}}$ mouse eyes (Figure 1B). These included corneal endothelial granulomatous keratic precipitates, Busacca and Koeppe nodules on the iris, and occasional pigmented deposits along the anterior lens capsule (Figure 1B). No corneal epithelial or stromal defects were observed in the slit-lamp examination.

En face infrared and blue autofluorescence cSLO images revealed significant hyperreflectivity and autofluorescence surrounding the periphery of the $\mathrm{ONH}$ in 8- to 9-week-old Asahl ${ }^{\mathrm{P} 361 \mathrm{R} / \mathrm{P} 361 \mathrm{R}}$ mice in comparison to control Asahl ${ }^{+/+}$ mice (Figure 1, C and D). Variable patches of hyperreflective and autofluorescent lesions were also observed in the fundus

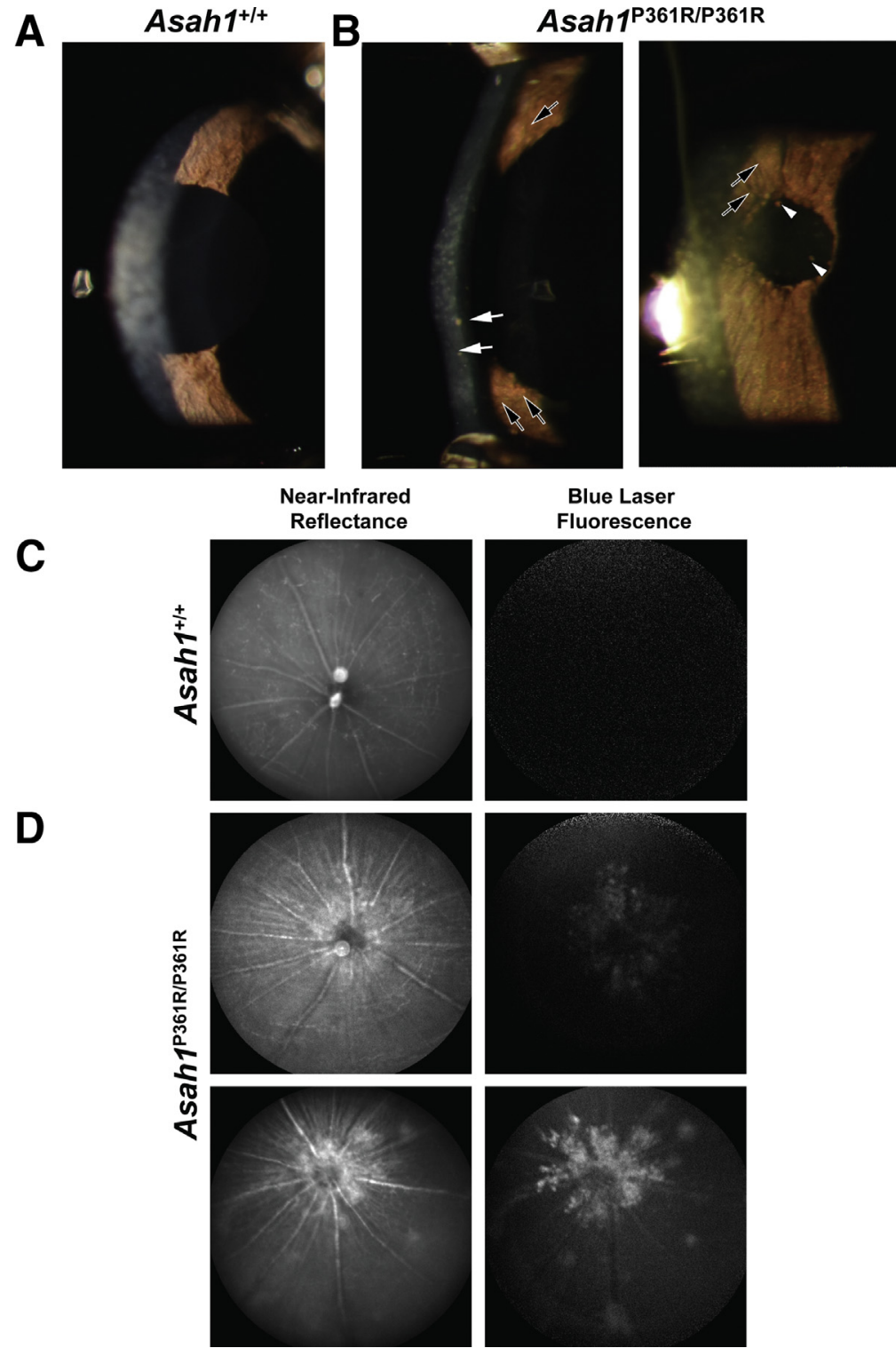

Figure 1 Anterior uveitis and optic nerve pathology in Asah1 $1^{\mathrm{P} 361 \mathrm{R} / \mathrm{P} 361 \mathrm{R}}$ mice. $\mathbf{A}$ and $\mathbf{B}$ : Slit-lamp images of the anterior section of 8- to 9-week-old control Asah1 ${ }^{+/+}$ (A) and $A s a h 1^{\mathrm{P} 361 \mathrm{R} / \mathrm{P} 361 \mathrm{R}}$ (B) mice. Granulomatous keratic precipitates (white arrows) and Busacca and Koeppe nodules (black arrows) indicate inflammation of the anterior segment of the Asah1 ${ }^{\text {P361R/P361R }}$ eye with clusters of pigment on anterior lens capsule (white arrowheads). C and D: Confocal scanning laser ophthalmoscope imaging was performed on 8- to 9-week-old control $\mathrm{Asah1}^{+/+}$(C) and Asah1 $^{\mathrm{P} 361 \mathrm{R} / \mathrm{P} 361 \mathrm{R}}$ (D) mice for near-infrared reflectance (IR; $810 \mathrm{~nm}$ ) and blue light autofluorescence (BAF; $486 \mathrm{~nm}$; emission filter, 525/50 nm). Representative IR and BAF images of healthy retinas from Asah $^{+/+}$mice showing no autofluorescence (C). Representative IR and BAF images from two Asah1 $1^{\mathrm{P361R} / \mathrm{P} 361 \mathrm{R}}$ mice each with varying levels of reflectivity and autofluorescence permeating from the optic nerve (D). 
of $A s a h 1^{\mathrm{P} 361 \mathrm{R} / \mathrm{P} 361 \mathrm{R}}$ mice (Figure 1D). Examination of 3- to 4-week-old mice using infrared and blue autofluorescence cSLO revealed no abnormal reflectivity in either $A s a h 1^{+/+}$or Asahl ${ }^{\mathrm{P} 361 \mathrm{R} / \mathrm{P} 361 \mathrm{R}}$ mice at that age (data not shown). Colored fundus images captured from 8- to 9-week-old mice appeared to correspond with cSLO images (Supplemental Figure S1). The 8- to 9-week-old Asahl ${ }^{\mathrm{P} 361 \mathrm{R} / \mathrm{P} 361 \mathrm{R}}$ mice had significant accumulation of white deposits near the $\mathrm{ONH}$, with occasional spots along the periphery of the fundus (Supplemental Figure S1).

To further investigate retinal involvement in $A \operatorname{sah1^{+/+}}$ and Asahl ${ }^{\mathrm{P} 361 \mathrm{R} / \mathrm{P} 361 \mathrm{R}}$ mice, OCT imaging was performed at two time points. The first time point was at 3 to 4 weeks of age (Figure 2, A and C); the second time point was at 8 to 9 weeks of age (Figure 2, B and D). Most OCT images obtained from 3- to 4-week-old Asahl $1^{\mathrm{P} 361 \mathrm{R} / \mathrm{P} 361 \mathrm{R}}$ mice appeared phenotypically to have normal retinal development (Figure 2C). However, some mice displayed less contrast within the individual retinal layers and on occasion there were hyperreflective spots within the vitreous (Figure 2C). This was most notable in the regions proximal to the $\mathrm{ONH}$. OCT at the later time point revealed more pronounced impairment in the retinal layers (Figure 2, D and G), in comparison with control Asahl ${ }^{+/+}$mice (Figure 2, B and E). Increased hyperreflectivity was most pronounced along the nerve fiber layer/retinal ganglion cell (RGC) layer, and the presence of hyperreflective specks was observed within the vitreous body of eyes from 8- to 9-week-old Asah1 ${ }^{\mathrm{P} 361 \mathrm{R} / \mathrm{P} 361 \mathrm{R}}$ mice (Figure 2G and Supplemental Video S1). After OCT imaging, H\&E staining of the corresponding globe confirmed retinal dysmorphia in the 8to 9-week-old Asahl $1^{\mathrm{P} 361 \mathrm{R} / \mathrm{P} 361 \mathrm{R}}$ mice (Figure 2H), in comparison with control Asahl $1^{+/+}$mice (Figure 2F).

\section{Impaired Retinal and Visual Function}

To test retinal function, dark-adapted, light-adapted, and flicker ERGs were performed on cohorts of both 3- to 4- and 8- to 9-week-old mice. A-waves, which in the dark-adapted condition measure rod photoreceptor function, were unchanged at lower intensities, but decreased starting at the $0 \log \mathrm{cd} \cdot$ second/ $\mathrm{m}^{2}$ flash intensity in 3- to 4-week-old Asahl ${ }^{\mathrm{P} 361 \mathrm{R} / \mathrm{P} 361 \mathrm{R}}$ mice (Figure 3, A and C). B-waves, which assess rod and bipolar cell function in the inner retina, were found decreased by the $-3 \log$ $\mathrm{cd} \cdot$ second $/ \mathrm{m}^{2}$ intensity in 3- to 4-week-old Asah1 $1^{\mathrm{P} 361 \mathrm{R} / \mathrm{P} 361 \mathrm{R}}$ mice (Figure 3, A and D). Dark-adapted, 3- to 4-week-old Asahl ${ }^{\mathrm{P} 361 \mathrm{R} / \mathrm{P} 361 \mathrm{R}}$ mice also displayed no changes to A-wave implicit time compared with age-matched controls (Supplemental Figure S1). That said, 3- to 4-week-old Asah1 $1^{\mathrm{P} 361 \mathrm{R} / \mathrm{P} 361 \mathrm{R}}$ mice displayed an increase in the B-wave implicit time at the highest flash intensity (Supplemental Figure S2, A and B). Dark-adapted ERGs were repeated on the same cohorts of mice at 8 to 9 weeks of age. There was a significant reduction in signal from the Asah $1^{\mathrm{P} 361 \mathrm{R} / \mathrm{P} 361 \mathrm{R}}$ mice (Figure 3B). A reduction in A- and B-wave amplitudes was detected at the $-3 \log \mathrm{cd} \cdot \mathrm{second} / \mathrm{m}^{2}$ flash intensity, as well as increased implicit times, and a negligible response was observed at the $-4 \log \mathrm{cd} \cdot \operatorname{second} / \mathrm{m}^{2}$ flash intensity (Figure 3, B, E, and F, and Supplemental Figure S2, C and D).

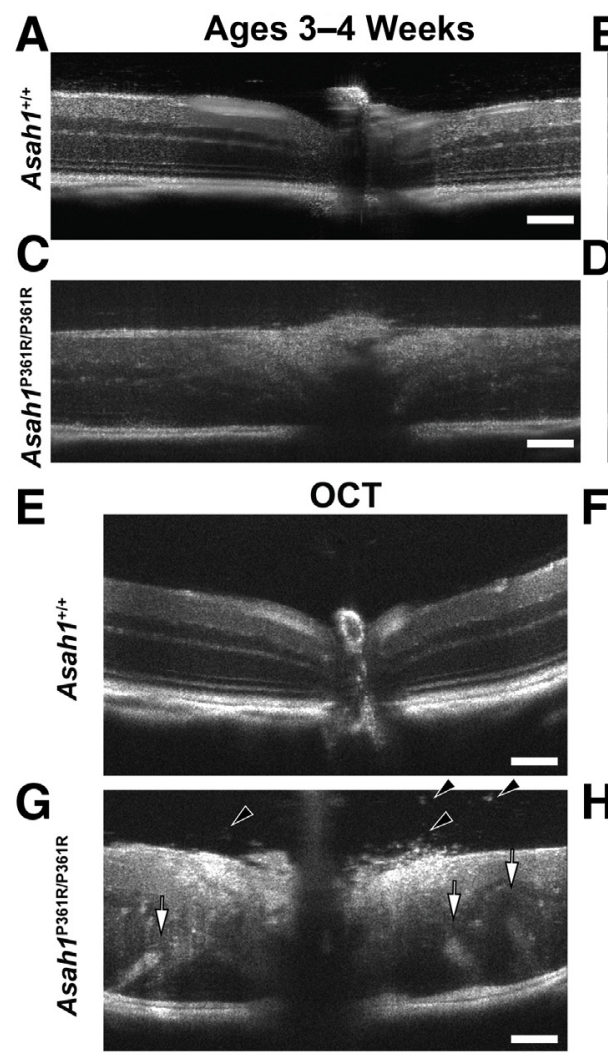

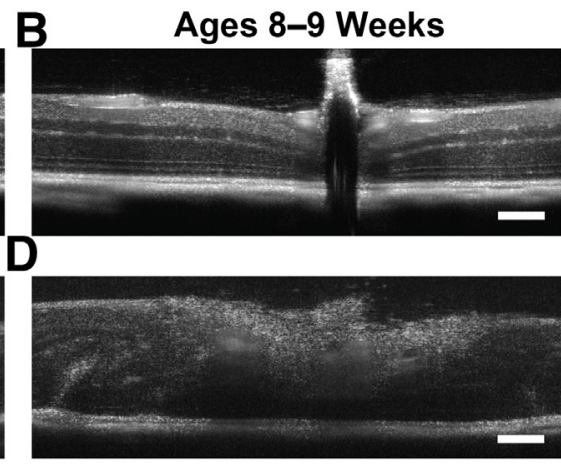

$\mathbf{F}$

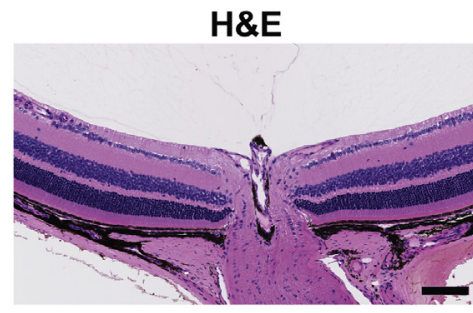

H

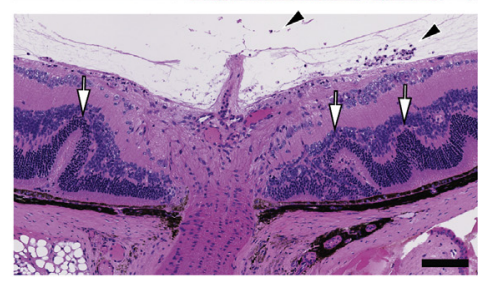

Figure 2 Optical coherence tomography (OCT) highlights retinal pathology in Asah1 $1^{\mathrm{P} 361 \mathrm{R} / \mathrm{P} 361 \mathrm{R}}$ mice. A-D: Representative OCT scans from the same eyes at 3 to 4 weeks of age and then again at 8 to 9 weeks of age from control $A s a h 1^{+/+}$and Asah1 $1^{\mathrm{P} 361 \mathrm{R} / \mathrm{P} 361 \mathrm{R}}$ mice. C and D: Longitudinal OCT scans of eyes from Asah1 $1^{\mathrm{P} 361 \mathrm{R} / \mathrm{P} 361 \mathrm{R}}$ mice at 3 to 4 and 8 to 9 weeks of age show increasing disorganization of retinal morphology as the animals age. E-H: OCT scans with corresponding hematoxylin and eosin (H\&E) micrographs of the same eyes from 8- to 9-week-old Asah1 $^{+/+}$and Asah1 $1^{\text {P361R/P361R }}$ mice. $\mathbf{G}$ and $\mathbf{H}$ : Inflammatory cells in the vitreal space (black arrowheads) and retinal folding (white arrows) are present in 8- to 9-week-old Asah1 $1^{\mathrm{P} 361 \mathrm{R} / \mathrm{P} 361 \mathrm{R}}$ mice. Scale bar $=100 \mu \mathrm{m}$. 
In the light-adapted ERG, which is an inference of cone function, a decrease in both A- and B-wave amplitudes as well as an increase in B-wave implicit time at the higher flash intensity in 3- to 4-week-old Asah1 ${ }^{\mathrm{P} 361 \mathrm{R} / \mathrm{P} 361 \mathrm{R}}$ mice
(Figure 3, G, I, and J, and Supplemental Figure S2, E and F) was detected. Flicker ERG, another indicator of cone function, revealed a decreased signal in both 5- and $15-\mathrm{Hz}$ rates of flicker in 3- to 4-week-old Asahl ${ }^{\mathrm{P} 361 \mathrm{R} / \mathrm{P} 361 \mathrm{R}}$ mice

Dark-Adapted ERG
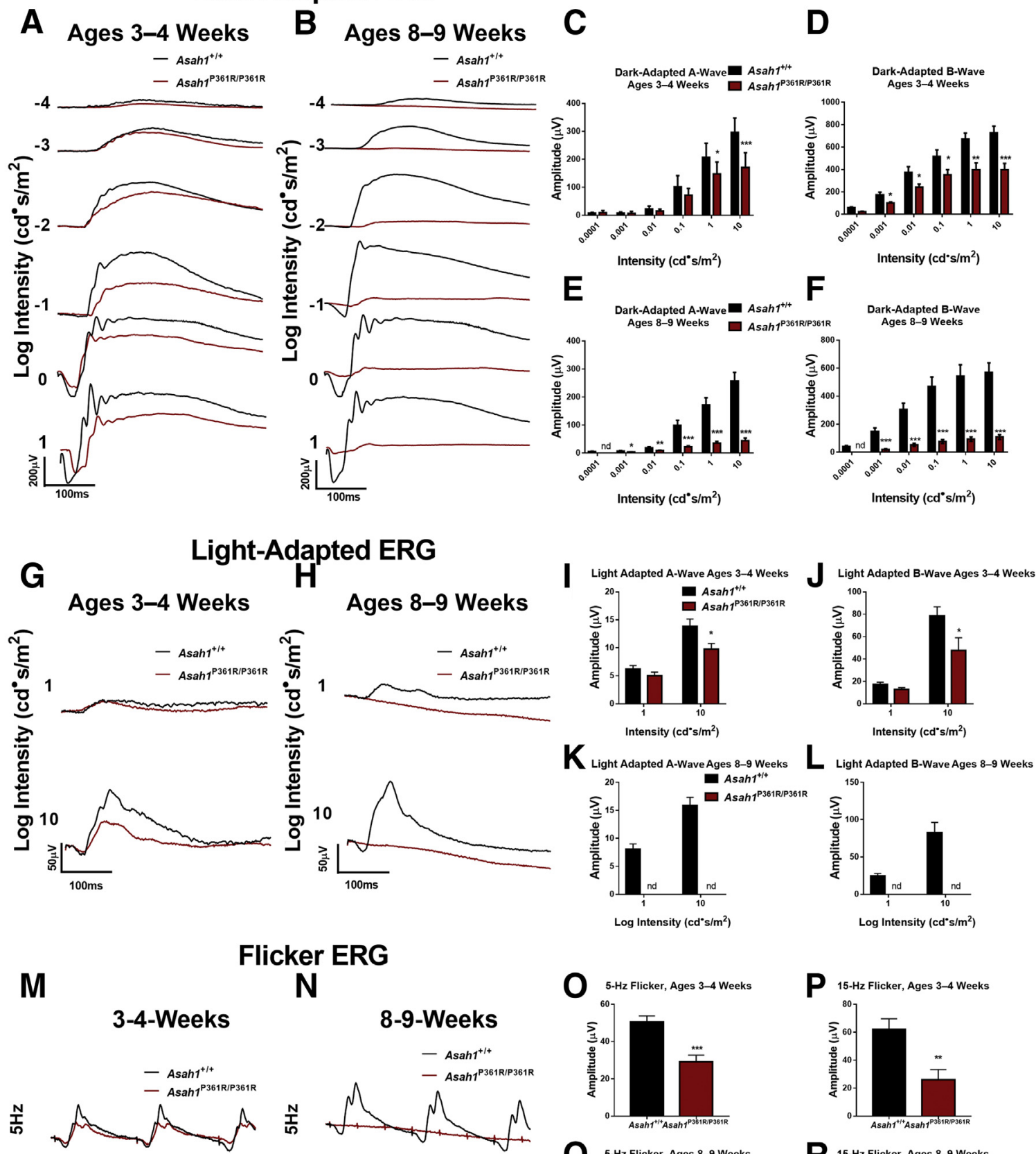

$\stackrel{\text { ñ }}{2}$
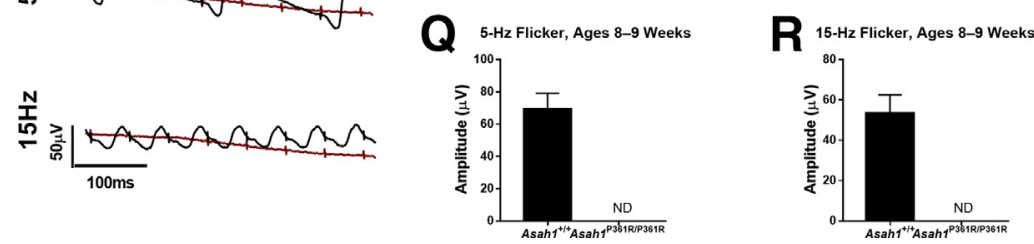

Figure 3 Electroretinogram (ERG) demonstrates progressive impairment in rod and cone function in Asah1 ${ }^{\mathrm{P} 361 \mathrm{R} / \mathrm{P} 361 \mathrm{R}}$ mice. A and B: Dark-adapted ERG

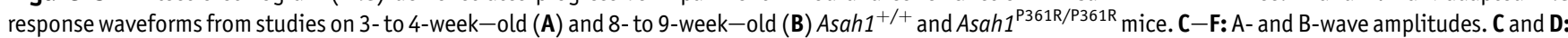
Waveforms were unrecordable for the $-4 \mathrm{log} \mathrm{cd} \cdot$ second $/ \mathrm{m}^{2}$ stimulus in 8- to 9-week-old Asah1 $1^{\mathrm{P} 361 \mathrm{R} / \mathrm{P} 361 \mathrm{R}}$ mice. $\mathbf{G}$ and $\mathbf{H}$ : Light-adapted ERG response waveforms

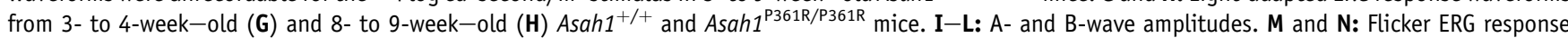

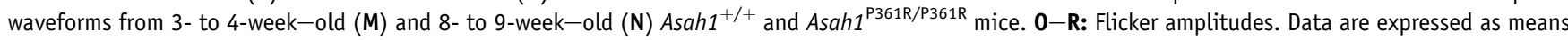
\pm SEM. $n=10$ animals for each genotype. ${ }^{*} P<0.05,{ }^{*} P<0.01$, and ${ }^{*} * P<0.001$. ND, no data because of an absence of a recordable waveform. 
(Figure 3, M, O, and P). Repeating light-adapted ERGs and flicker ERG on the same mice at 8 to 9 weeks of age demonstrated a lack of response from the Asahl ${ }^{\mathrm{P} 361 \mathrm{R} / \mathrm{P} 361 \mathrm{R}}$ mice (Figure 3, H, K, L, N, Q, and R, and Supplemental Figures $\mathrm{S} 2, \mathrm{G}$ and $\mathrm{H}$ ).

To further validate visual impairment in this model, a modified visual cliff test was performed on 8- to 9-

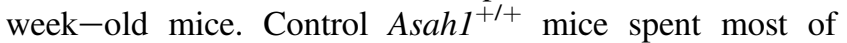
their time within the ground side of the apparatus (Figure 4, $\mathrm{A}$ and $\mathrm{C}-\mathrm{F}$ ). They also traveled a greater distance. In contrast, Asahl ${ }^{\mathrm{P} 361 \mathrm{R} / \mathrm{P} 361 \mathrm{R}}$ mice demonstrated no preference for ground or air zones, spending roughly equal time in both sectors. They also traveled an equal total distance within the ground and air side (Figure 4, B-F). Although other behavioral deficits have been previously demonstrated in Asahl ${ }^{\mathrm{P} 361 \mathrm{R} / \mathrm{P} 361 \mathrm{R}}$ mice, ${ }^{21}$ the results from this modified visual cliff test and the ERG data together suggest significant visual impairment in these animals.

\section{Increased Retinal Thickness}

Asahl $1^{\mathrm{P} 361 \mathrm{R} / \mathrm{P} 361 \mathrm{R}}$ mice are smaller than age-matched controls. By 4 to 5 weeks of age, they also start to progressively lose weight until they succumb to the disorder. ${ }^{20}$ During examination of the eyes, Asahl $1^{\mathrm{P} 361 \mathrm{R} / \mathrm{P} 361 \mathrm{R}}$ mice had smaller interpalpebral fissures compared with age-matched controls (Supplemental Figure S3). To assess whether eye development was affected, gross measurements were performed on micrographs obtained from H\&E-stained globe sections. Measurements revealed no significant differences in globe or lens diameter in 3- to 4- and 8- to 9-week-old AsahI ${ }^{+/+}$ and Asahl $^{\mathrm{P} 361 \mathrm{R} / \mathrm{P} 361 \mathrm{R}}$ mice, respectively (Supplemental Figure S4, A-D). Measurements of the anterior chamber also revealed no differences in the thickness of the corneal epithelium and stroma between $A s a h 1^{+/+}$and $A s a h 1^{\mathrm{P} 361 \mathrm{R} /}$ P361R mice at both 3 to 4 and 8 to 9 weeks of age (Supplemental Figure S4, E and F). This phenotype may be

A
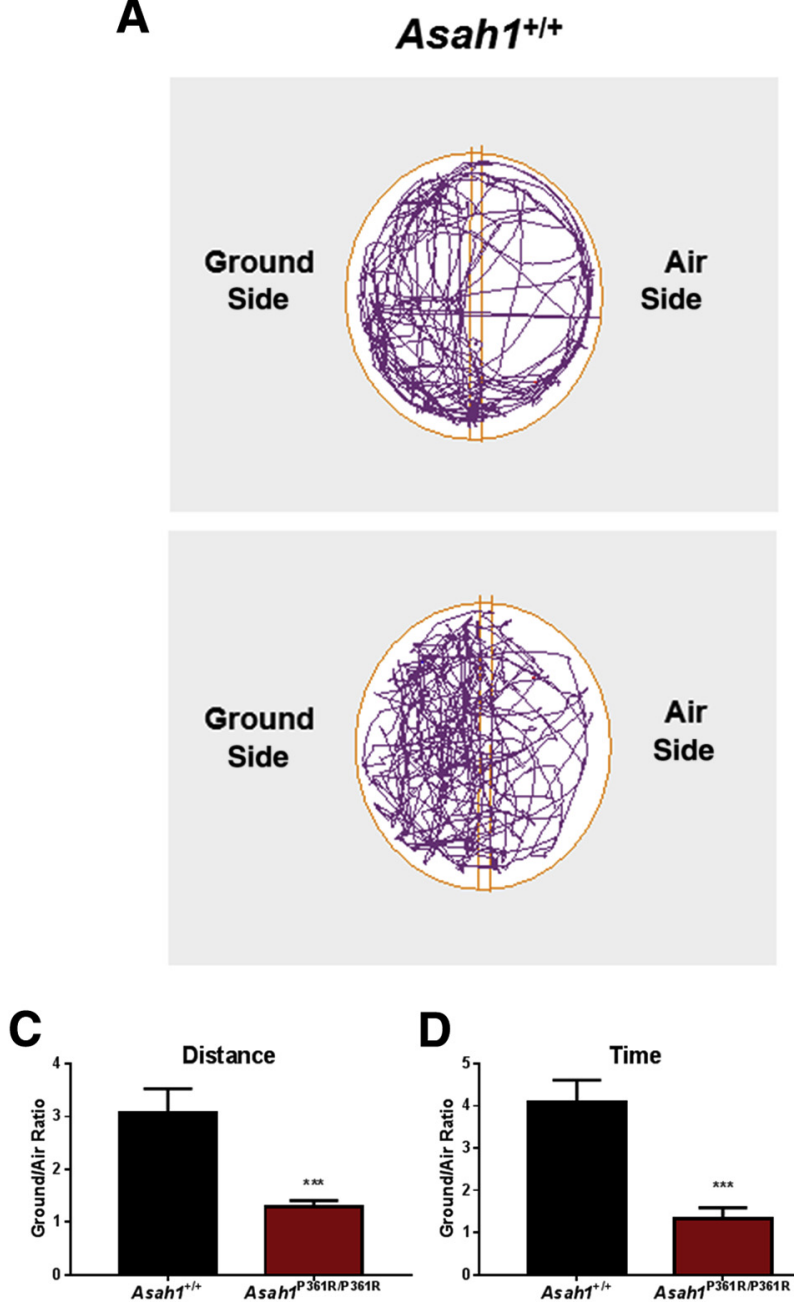

D

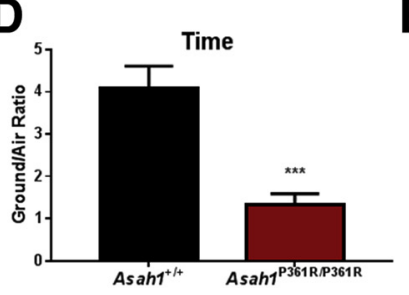

B

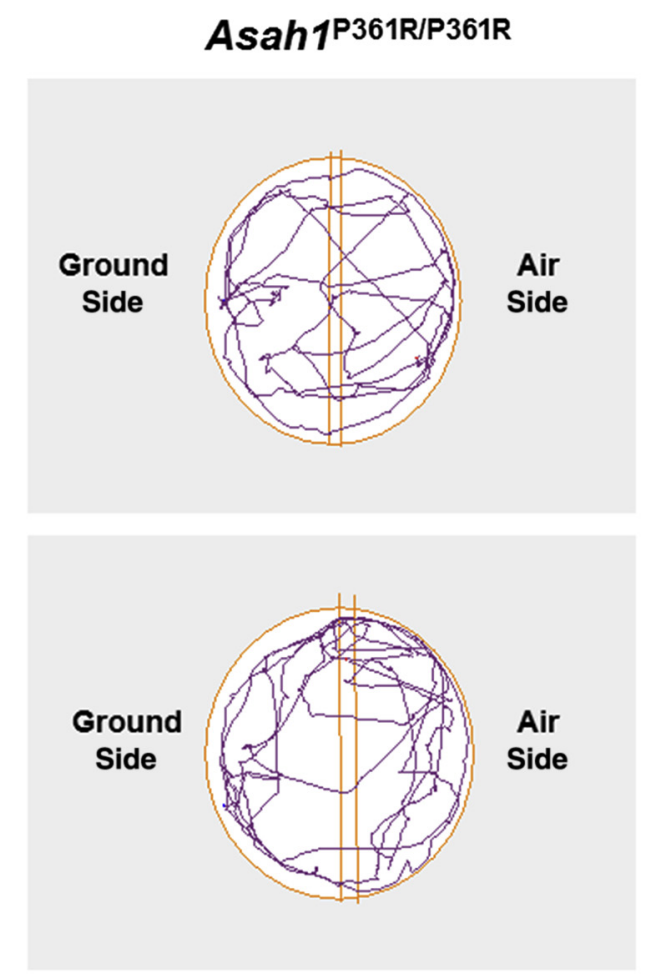

E

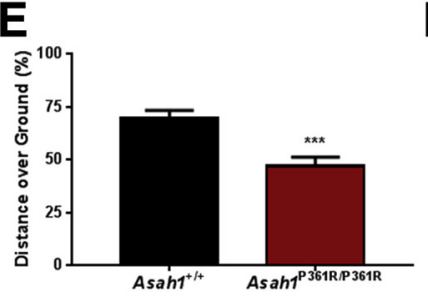

$\mathbf{F}$

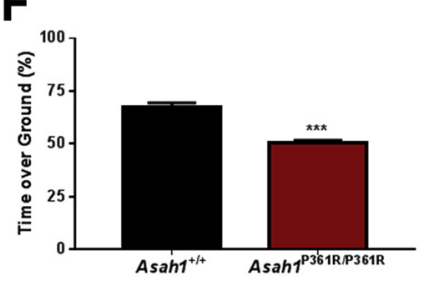

Figure 4 Visual cliff test reveals perturbed depth perception in Asah1 ${ }^{\text {P361R/P361R }}$ mice. A and B: Representative movement traces of 8- to 9-week-old Asah1 $^{+/+}(\mathbf{A})$ and Asah1 ${ }^{\mathrm{P} 361 \mathrm{R} / \mathrm{P} 361 \mathrm{R}}$ (B) mice during the visual cliff test. Distance traveled in each zone expressed as ground/air ratio. C: Asah1 $1^{\mathrm{P} 361 \mathrm{R} / \mathrm{P} 361 \mathrm{R}}$ mice spend equal amounts of time in both the ground side and the air side. D: Duration spent in each zone expressed as ground/air ratio. $\mathbf{E}$ and $\mathbf{F}$ : Percentage of the distance traveled $(\mathbf{E})$ and the time spent $(\mathbf{F})$ on the ground side. Data are expressed as means \pm SEM. $n=15$ animals for each genotype. $* * *<0.001$. 
the clinical equivalent of ptosis or blepharophimosis, which has not been described in FD.

Surprisingly, Asah1 ${ }^{\mathrm{P} 361 \mathrm{R} / \mathrm{P} 361 \mathrm{R}}$ mice displayed increased retinal thickness as early as 3 to 4 weeks of age when compared with age-matched $\mathrm{Asahl}^{+/+}$mice (Figure 5, A and B). Specifically, by 3 to 4 weeks of age, the outer nuclear layer was significantly thicker (Figure 5C). By 8 to 9 weeks of age, increased thickness was observed in both the inner nuclear layer and outer nuclear layer (Figure 5D). To validate our histology measurements, retinal thickness was analyzed from our previous OCT images with OCT retinal analysis software. ${ }^{23}$ Analyses of OCT images revealed that 3- to 4-week-old Asahl ${ }^{\text {P361R/P361R }}$ mice exhibited increased nasal and temporal retinal thickness in comparison to age-matched $\mathrm{Asahl}^{+/+}$mice (Figure 5E). This increased thickness became more progressive by 8 to 9 weeks (Figure 5, F and $\mathrm{H}$ ). No changes in thickness were seen between 3- to 4- and 8- to 9-week-old Asah1 ${ }^{+/+}$mice (Figure 5G).

\section{Variable Penetrance of Retinal Dysplasia}

To examine the presence of retinal dysplasia, H\&E-stained retinas were examined to evaluate their morphology. All of the retinas from 3- to 4-week-old control Asah1 ${ }^{+/+}$and 3to 4-week-old Asahl $1^{\mathrm{P} 361 \mathrm{R} / \mathrm{P} 361 \mathrm{R}}$ mice showed no dysplasia
(Figure 6, A and B). Examination of 8- to 9-week-old Asah1 $1^{\mathrm{P} 361 \mathrm{R} / \mathrm{P} 361 \mathrm{R}}$ mice, however, revealed a range in retinal dysplasia (Figure 6, C-F). Approximately 25\% of globes from $A \operatorname{sah1} 1^{\mathrm{P} 361 \mathrm{R} / \mathrm{P} 361 \mathrm{R}}$ mice were within normal limits, $45 \%$ developed an intermediate degree of dysplasia, and $30 \%$ had severe retinal folding. Retinal dysplasia was most pronounced in regions closest to the ONH. Mice that developed severe retinal disturbances often had involvement of multiple layers, with folds even reaching into the vitreous body (Figure 6F).

\section{Inflammation, Astrogliosis, and Storage Pathology in} the Retina, $\mathrm{ONH}$, and Unmyelinated Optic Nerve

Inflammatory cells were observed in the eyes of 8- to 9week-old Asah1 $1^{\mathrm{P} 361 \mathrm{R} / \mathrm{P} 361 \mathrm{R}}$ mice (Figure 7, B, E, G, I, and

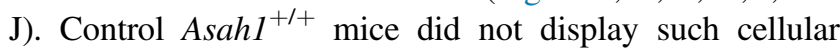
recruitment (Figure 7, A, E, and $\mathrm{H}$ ). Infiltrating inflammatory cells were observed in both the anterior chamber and vitreous humor of 8- to 9-week-old Asah1 ${ }^{\mathrm{P} 361 \mathrm{R} / \mathrm{P} 361 \mathrm{R}}$ mice (Figure 7B). An increased abundance of inflammatory cells was most notable in the vitreal region above the $\mathrm{ONH}$, presumably where the central retinal vein and artery are located (Figure 7, F and G).

Next, IHC staining was performed for Mac-2 (a macrophage marker) on globes from 8- to 9-week-old mice.
A

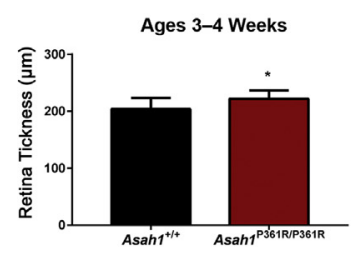

C
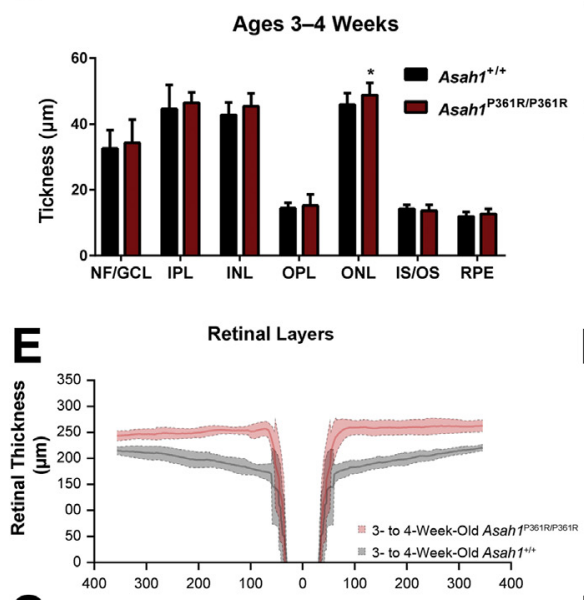

$G$

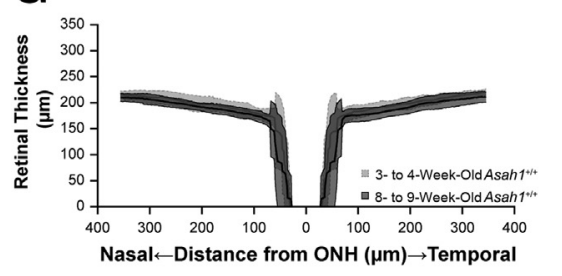

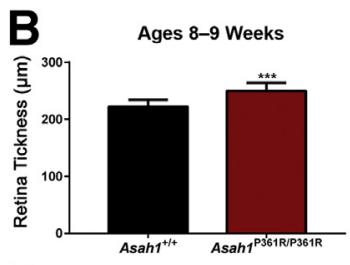

D

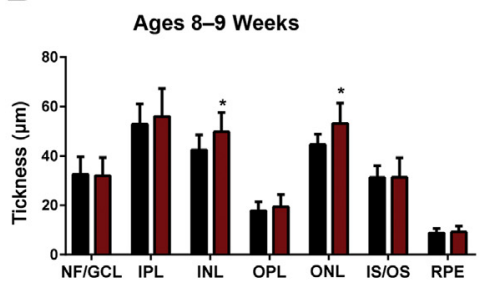

$\mathbf{F}$

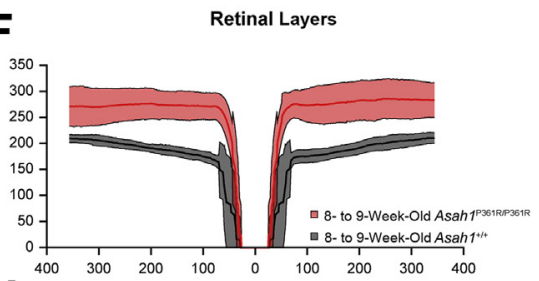

H

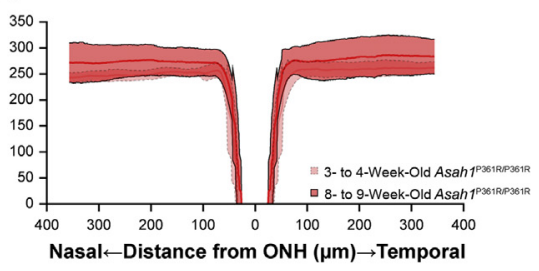

Figure 5 Increased retinal thickness in Asah1 $1^{\mathrm{P} 361 \mathrm{R} / \mathrm{P} 361 \mathrm{R}}$ mice. A-D: Morphometric analyses of retinas from 3- to 4-week-old ( $\mathbf{A}$ and $\mathbf{C}$ ) and 8- to 9-week-old (B and D) control Asah1 ${ }^{+/+}$mice and test Asah1 $1^{\mathrm{P} 361 \mathrm{R} / \mathrm{P} 361 \mathrm{R}}$ mice from hematoxylin and eosin-stained sections. E-H: Retinal thickness plot generated from optical coherence tomography Bscans on samples from 3- to 4- and 8- to 9-weekold $A s a h 1^{+/+}$mice and $A s a h 1^{\text {P361R/P361R }}$ mice. Retinal thickness is significantly increased in the Asah1 $1^{\mathrm{P} 361 \mathrm{R} / \mathrm{P} 361 \mathrm{R}}$ mice when an $n$-way analysis of variance is performed for factors that included genotype, age, and retinal location. $\mathbf{E}$ and $\mathbf{F}$ : $P<0.0001$. Data are expressed as means \pm SEM (A-D) and means \pm SD (E-H). $n=10$ animals per group (A-D); $n=6$ to 10 animals per group (E-H). ${ }^{*} P<0.05,{ }^{* * *} P<0.001$. GCL, ganglion cell layer; INL, inner nuclear layer; IPL, inner plexiform layer; IS, inner segment; $\mathrm{NF}$, nerve fiber; $\mathrm{ONH}$, optic nerve head; $\mathrm{ONL}$, outer nuclear layer; $\mathrm{OPL}$, outer plexiform layer; OS, outer segment; RPE, retinal pigment epithelium. 
Many of these inflammatory cells were observed in Asahl ${ }^{\mathrm{P} 361 \mathrm{R} / \mathrm{P} 361 \mathrm{R}}$ mice (Figure 7, H-J). Although they were commonly localized around the $\mathrm{ONH}$, macrophages were also observed within the vessels of the RGC layer and along the choroid/pigment epithelium layer in regions where retinal folding occurred (Figure 7, I and J). In the 8- to 9week-old Asahl $1^{\mathrm{P} 361 \mathrm{R} / \mathrm{P} 361 \mathrm{R}}$ mice that developed significant retinal folding, detachment of the retina often occurred, as well as subretinal hemorrhages (Figure $7 \mathrm{G}$ ).

IHC staining for cathepsin D revealed an increase in lysosomal staining, particularly in RGC and inner nuclear retinal layers of 8- to 9-week-old Asahl ${ }^{\mathrm{P} 361 \mathrm{R} / \mathrm{P} 361 \mathrm{R}}$ mice compared with controls (Figure 7, C and D). Examination of the nerve fiber/RGC layers of 8- to 9-week-old Asahl $1^{\mathrm{P} 361 \mathrm{R} /}$
P361R mice revealed increased vacuolation and a more intense granular cathepsin D staining (Figure 7D). Of the 8to 9-week-old Asahl $1^{\mathrm{P} 361 \mathrm{R} / \mathrm{P} 361 \mathrm{R}}$ mice that had severe retinal dysplasia, the nerve fiber/RGC layer showed degeneration and sloughing (Figure $7 \mathrm{G}$ ).

To further characterize neuroinflammation, retinal sections were assessed from 8- to 9-week-old mice by immunofluorescence staining for GFAP, a label for glial cells such as astrocytes and Müller cells. Staining was also performed for Iba1, a marker for activated microglia (Figure 7, K and L). The retina of Asahl $1^{\mathrm{P} 361 \mathrm{R} / \mathrm{P} 361 \mathrm{R}}$ mice did not contain many cells that were positive for Iba1. On occasion, some microglia-like cells that had branching projections in 8- to 9-week-old Asahl $1^{\mathrm{P} 361 \mathrm{R} / \mathrm{P} 361 \mathrm{R}}$ mice were
A

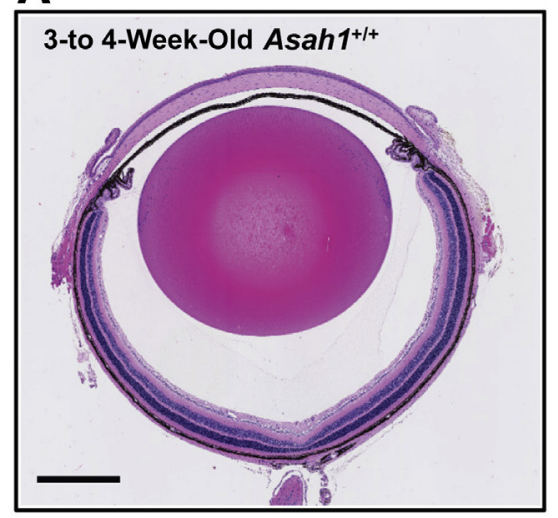

C

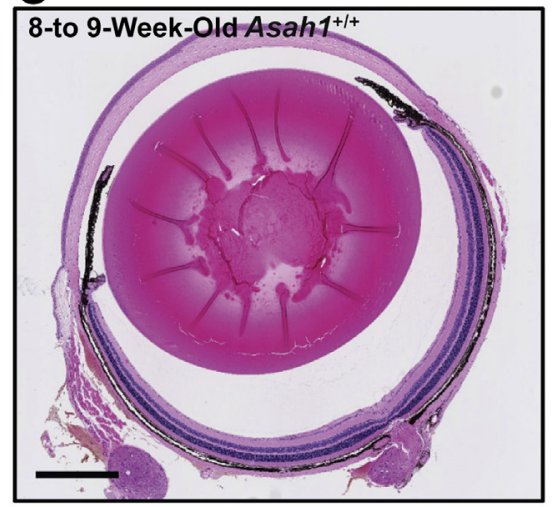

$E$

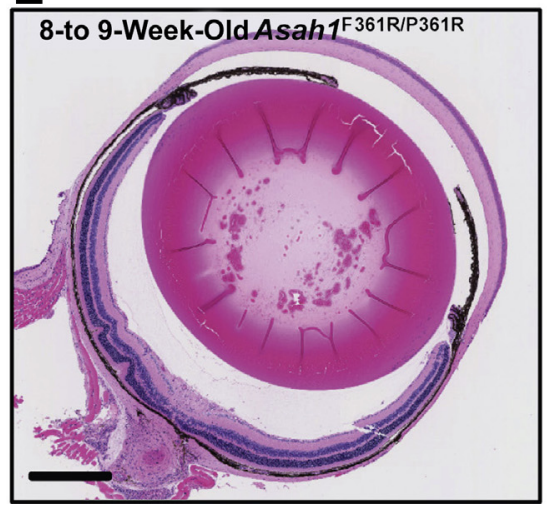

\section{B}

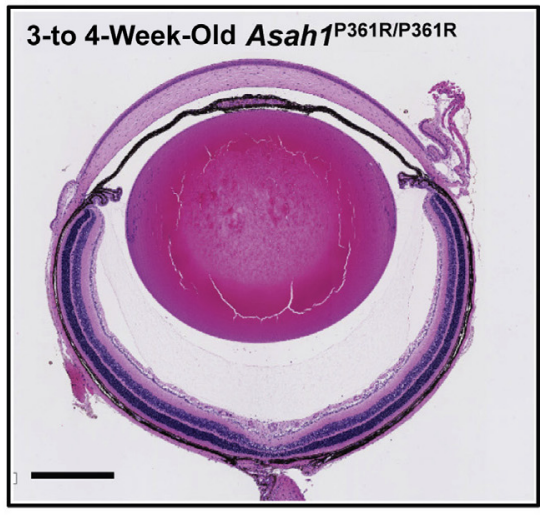

D

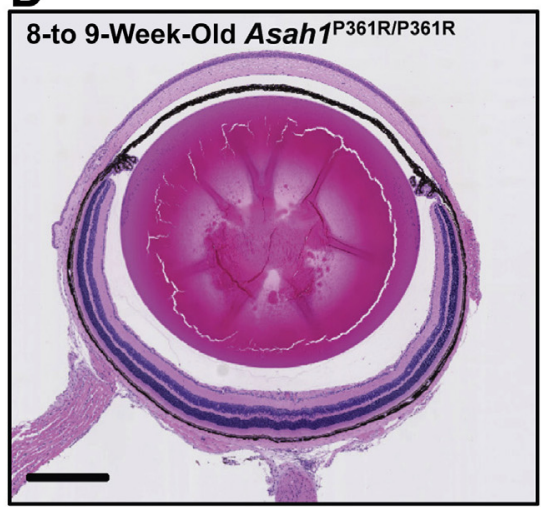

$F$

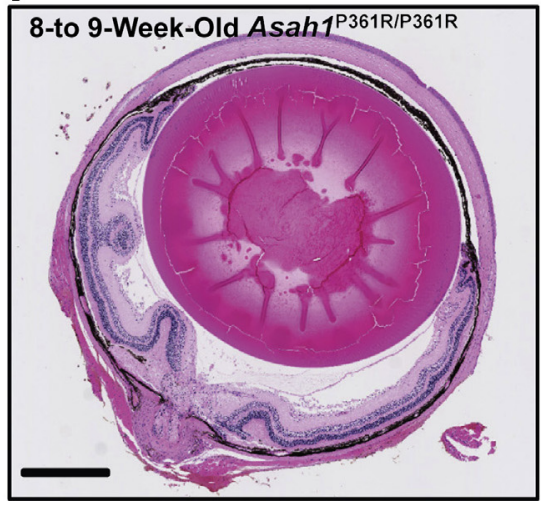

Figure 6 Varying degree of retinal dysplasia in Asah1 ${ }^{\text {P361R/P361R }}$ mice. A-F: Light micrographs of hematoxylin and eosin-stained globe cross sections from 3- to 4- and 8- to 9-week-old Asah1 ${ }^{+/+}$ and Asah1 ${ }^{\mathrm{P} 361 \mathrm{R} / \mathrm{P} 361 \mathrm{R}}$ mice. D-F: A varying degree of retinal dysplasia is observed in 8- to 9-week-old Asah1 ${ }^{\mathrm{P} 361 \mathrm{R} / \mathrm{P} 361 \mathrm{R}}$ mice. Retinal morphology is within normal limits for all 8- to 9-week-old Asah1 ${ }^{+/+}$ mice and 3- to 4-week-old Asah1 $1^{\mathrm{P} 361 \mathrm{R} / \mathrm{P} 361 \mathrm{R}}$ mice globes that were scored. In 8- to 9-week-old Asah1 $1^{\text {P361R/P361R }}$ mice, morphology scoring reveals $30 \%$ of globes with severe dysplasia, $45 \%$ of globes with intermediate dysplasia, and $25 \%$ of globes within normal limits. $n=20$ retinal samples per group. Scale bar $=500 \mu \mathrm{m}$. 

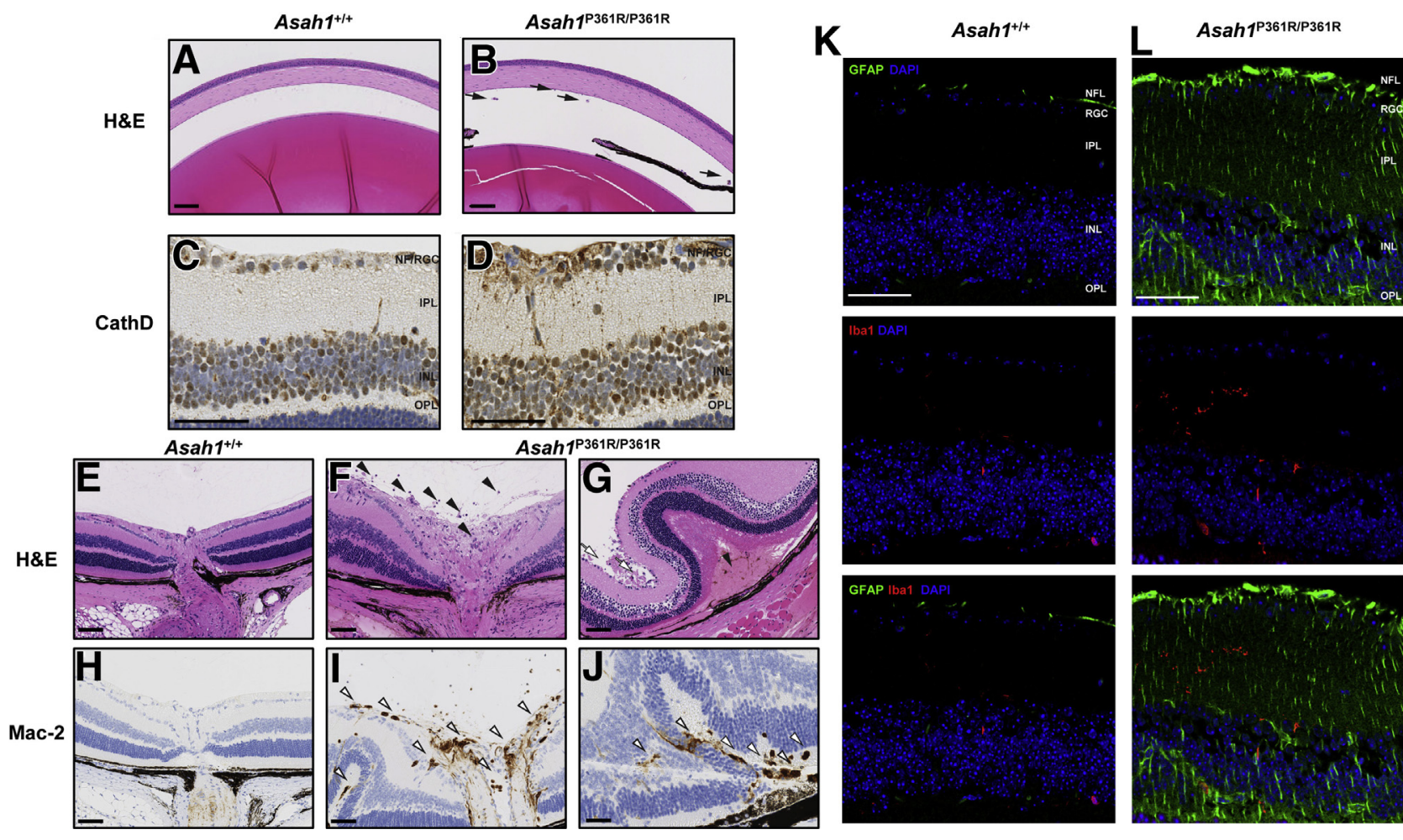

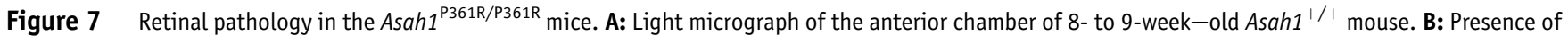
inflammatory cells in anterior chamber (black arrows) in 8- to 9-week-old Asah1 ${ }^{\text {P361R/P361R }}$ mouse. C and D: Immunohistochemistry (IHC) staining for

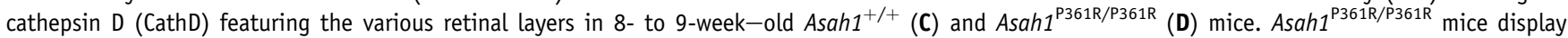
increased and more intense staining for CathD. E: Light micrograph of the retina and optic nerve head (ONH) from an 8- to 9-week-old Asah $1^{+/+}$mouse. F: Numerous inflammatory cells (black arrowheads) can be seen along the $0 \mathrm{NH}$ in sections from 8- to 9-week-old Asah1 ${ }^{\mathrm{P} 361 \mathrm{R} / \mathrm{P} 361 \mathrm{R}}$ mice. G: In Asah $1^{\mathrm{P} 361 \mathrm{R} / \mathrm{P} 361 \mathrm{R}}$ mice that exhibit significant retinal dysplasia, loss/sloughing of the retinal ganglion cell (RGC) layer is observed (white arrows), as well as retinal detachment

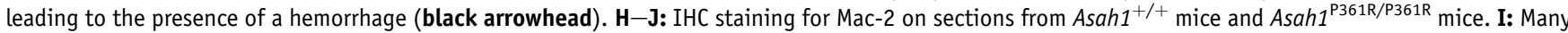
of the invading inflammatory cells near the RGC and optic nerve vessels are macrophages (white arrowheads). J: Invading cells (white arrowheads) can also be detected in the choroid layers, where there are retinal folds. $\mathbf{K}$ and $\mathbf{L}$ : Immunofluorescence staining for glial fibrillary acidic protein (GFAP), ionized calcium-

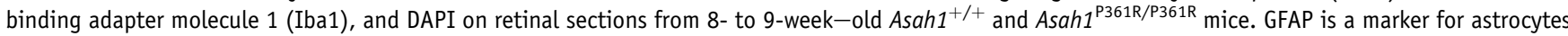
and Müller cells, and Iba1 is a marker for microglia and macrophages. Scale bar $=50 \mu \mathrm{m}$. H\&E, hematoxylin and eosin; INL, inner nuclear layer; IPL, inner plexiform layer; NFL, nerve fiber layer; OPL, outer plexiform layer.

observed; however, such occurrences were infrequent, and those cells were not found to be localized to one particular region. Furthermore, IHC on serial retinal sections revealed areas where Mac-2 staining was positive and Ibal was negative (Supplemental Figure S5). This suggests that these recruited cells are predominantly macrophages.

Increased GFAP staining was found on multiple retinal layers, but most intense in the nerve fiber/RGC layer of retinal sections from 8- to 9-week-old Asahl ${ }^{\mathrm{P} 361 \mathrm{R} / \mathrm{P} 361 \mathrm{R}}$ mice (Figure $7 \mathrm{~L}$ ). GFAP staining was also positive along the inner plexiform layer, the inner nuclear layer, and the outer plexiform layer of retinal sections from mutant mice. This observation suggests astrocytosis and Müller cell activation in the retina of the ACDase-deficient mice. To assess whether activation of microglia was present in the visual system, retinal tissue was stained for Iba1. On occasion, we observed an increased number of Iba1positive cells; however, phenotypically, these labeled cells appeared similar to those from wild-type animals (Figure 7L).
Ultrastructural analyses of the retina and unmyelinated portion of the ON in 8- to 9-week-old Asahl ${ }^{\mathrm{P} 361 \mathrm{R} / \mathrm{P} 361 \mathrm{R}}$ mice revealed extensive storage pathology in a range of cell types that was absent in samples from 8- to 9-week-old control mice (Figure 8, A-C). Ganglion cells in 8- to 9week-old Asahl ${ }^{\mathrm{P} 361 \mathrm{R} / \mathrm{P} 361 \mathrm{R}}$ mice contained an excess of zebra-like storage bodies (Figure 8, D and E). Zebra bodies were also present in endothelial cells of the vessels of the inner plexiform layer (Figure 8F). The inner plexiform layer also contained abnormal storage vacuoles in the abundant astrocytic processes (Figure 8, G-I) and abnormal macrophage-like cells with an excess of curved-linear tubular body-like profiles in the vicinity of capillaries (Figure $8 \mathrm{H}$ ) and zebra body-like storage vacuoles in the astrocytic processes (Figure 8I). In addition, storage vacuoles were observed within endothelial cells on the central retinal vessels of the ONH (Figure 8F). Similar to the rest of the retina and central nervous system, ${ }^{21}$ the perivascular space of the $\mathrm{ONH}$ contained storage-laden, macrophage-like abnormal cells (Supplemental Figure S6). Curved-linear 
tubular body-like storage vacuoles were also observed within endothelial cells of the choroid capillaries and inside melanosome-containing cells along the outer choroid (Supplemental Figure S7). Last, zebra bodies (indicating storage) were also present within scleral fibroblasts (Supplemental Figure S7).

\section{Pathology of the Myelinated Optic Nerve}

Representative light micrographs of H\&E-stained ON tissue from 8- to 9-week-old Asahl ${ }^{+/+}$and Asahl P361R/P361R mice are shown in Figure 9, A and B. Asahl $1^{\mathrm{P} 361 \mathrm{R} / \mathrm{P} 361 \mathrm{R}}$ mice displayed a thickening of the ON pial sheath (Figure 9B). $\mathrm{H} \& \mathrm{E}$ staining of ON tissue from 8- to 9-week-old Asahl $1^{\mathrm{P} 361 \mathrm{R} / \mathrm{P} 361 \mathrm{R}}$ mice also revealed the presence of mononuclear cellular infiltrates with abundant vacuolated cytoplasm and/or cytoplasm distended with granular material that preferentially accumulated in the vicinity of the optic vein (Figure 9B). When the corresponding ON tissue from 8- to 9-week-old mice was stained with Luxol fast blue, the staining on Asahl ${ }^{\mathrm{P} 361 \mathrm{R} / \mathrm{P} 361 \mathrm{R}}$ mice $\mathrm{ON}$ tissue appeared less intense (Figure 9, C and D).

IHC staining for Mac-2 confirmed the presence of infiltrating macrophages along the $\mathrm{ON}$ track in samples from 8- to

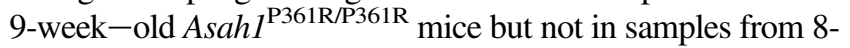
to 9-week-old Asahl ${ }^{+/+}$mice (Figure 9, E and F). Sections of ON tissue from 8- to 9-week-old Asahl $1^{\mathrm{P} 361 \mathrm{R} / \mathrm{P} 361 \mathrm{R}}$ mice displayed greater GFAP staining than controls (Figure 9, G and $\mathrm{H}$ ). This suggests that astrocytosis is also affecting the $\mathrm{ON}$ tissue of $A s a h 1^{\mathrm{P} 361 \mathrm{R} / \mathrm{P} 361 \mathrm{R}}$ mice.
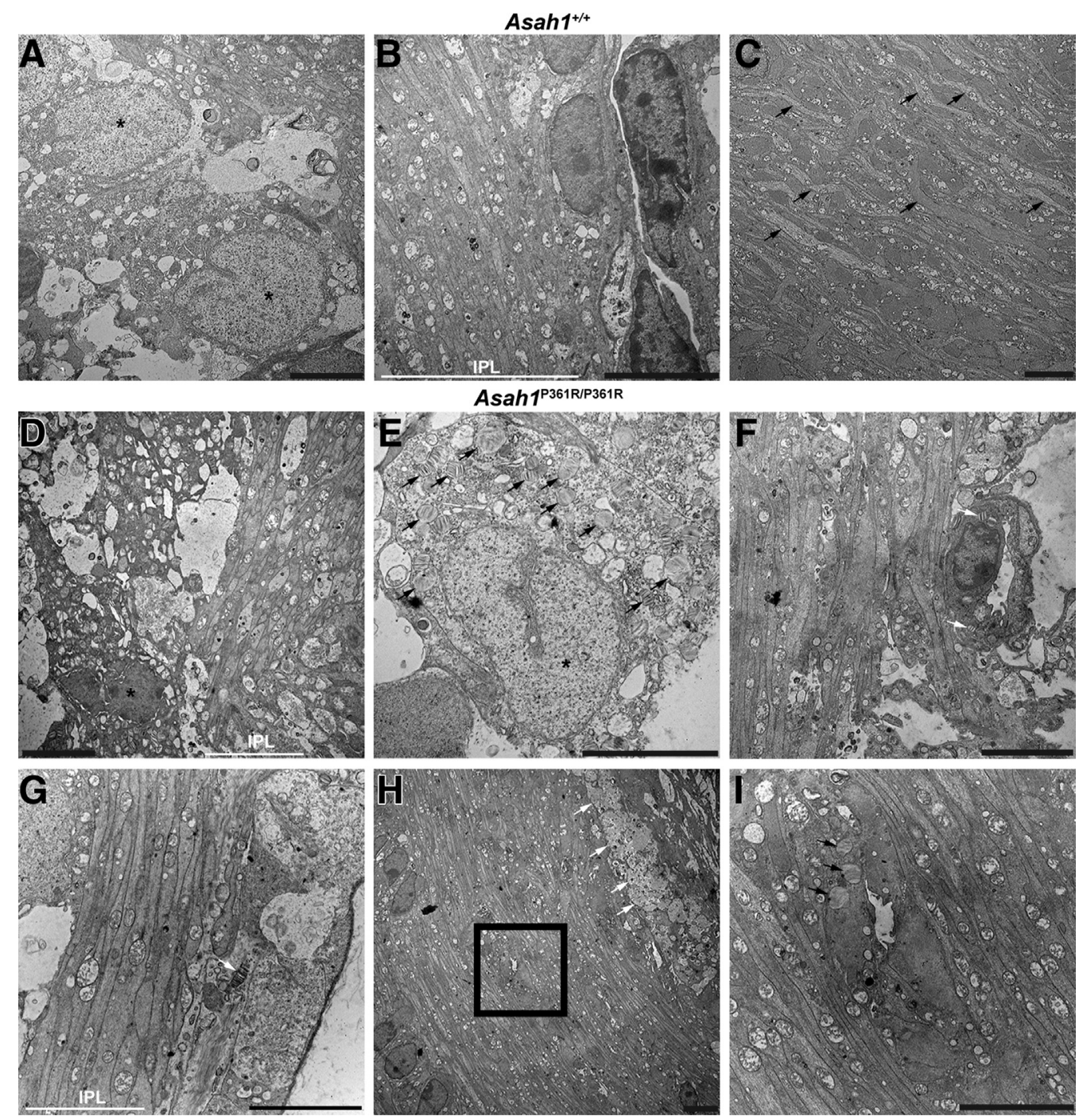

Figure 8 Retinal and unmyelinated on ultrastructure pathology in the Asah1 ${ }^{\mathrm{P} 361 \mathrm{R} / \mathrm{P} 361 \mathrm{R}}$ mice. A: Electron micrographs highlighting the ganglion cells

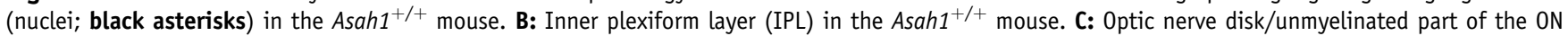

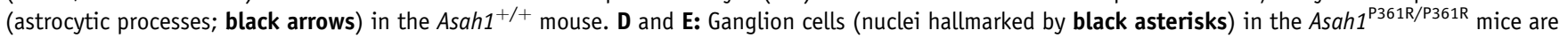
with numerous zebra-like storage vacuoles in their cytoplasm (black arrows). F-I: White arrows highlight zebra body-like storage profiles in the endothelial cell (F); zebra body-like storage vacuole (white arrow) in the astrocytic process (G); macrophage-like cells (white arrows) laden with curved-linear tubular body-like storage bodies (H); and zebra body-like storage vacuoles (black arrows) in the astrocytic processes (I; image corresponds to the boxed area in $\mathbf{H}$ ). Scale bar $=5 \mu \mathrm{m}$. 
Ultrastructure analysis of $\mathrm{ON}$ sections from 8- to 9week-old $A s a h 1^{\mathrm{P} 361 \mathrm{R} / \mathrm{P} 361 \mathrm{R}}$ mice revealed abnormal storage in macrophages accumulating in the intraneuronal perivascular spaces (Figure 10, A-C). These macrophage- and fibroblast-like cells contained curved-linear tubular body storage in vacuoles. ON from Asah1 $1^{\mathrm{P} 361 \mathrm{R} / \mathrm{P} 361 \mathrm{R}}$ mice also showed discernible storage vacuoles in astrocytes and zebralike storage vacuoles within the cytoplasm of oligodendrocytes (Figure 10, D-I). Abnormal storage vacuoles were also present in the endothelial cells of vessels (both pial and intraneuronal) and in capillaries (Supplemental Figure S8).

\section{Neuroaxonal Dystrophy and Reduced Axonal Density}

Ultrastructure analyses of tissue (interior and periphery) from 8- to 9-week-old animals revealed that the $\mathrm{ON}$ of mutant mice had a qualitative reduction in axon density compared with controls (Figure 10, J-L). Signs of neuroaxonal dystrophy in some axons via the formation of axonal spheroids were also observed in the ON of $A s a h 1^{\mathrm{P} 361 \mathrm{R} / \mathrm{P} 361 \mathrm{R}}$ mice (Figure 10, $\mathrm{K}$ and $\mathrm{L}$ ).

To assess myelination, the G-ratio (axon diameter/fiber diameter; where fiber diameter $=$ axon diameter + myelin sheath thickness) of the ON from 8- to 9-week-old mice was measured. The analysis revealed a significant reduction in the Gratio in samples from $A s a h 1^{\mathrm{P} 361 \mathrm{R} / \mathrm{P} 361 \mathrm{R}}$ mice in comparison to those from control Asahl $1^{+/+}$mice (Figure 10M). However, no differences were detected in the $\mathrm{ON}$ axon diameter between 8- to 9-week-old Asah1 ${ }^{+/+}$and $A s a h 1^{\mathrm{P} 361 \mathrm{R} / \mathrm{P} 361 \mathrm{R}}$ mice (Figure $10 \mathrm{~N}$ ). Further evaluation revealed a reduction in the density of myelinated axons in $A s a h 1^{\mathrm{P} 361 \mathrm{R} / \mathrm{P} 361 \mathrm{R}} \mathrm{ONs}$; however, of the axons that were assessed, no changes in the percentage of myelinated axons were observed (Figure 10, O and P).

\section{Altered Sphingolipid Profile in the Retina}

Ceramide, sphingomyelin (SM), monohexosylceramide (MHC), Sph, and S1P were measured via liquid chromatography-mass spectrometry in retinal lipid extracts from both 3- to 4- and 8- to 9-week-old Asahl ${ }^{+/+}$and Asah1 $1^{\mathrm{P} 361 \mathrm{R} / \mathrm{P} 361 \mathrm{R}}$ mice. $\mathrm{C} 1 \mathrm{P}$ was measured via liquid chromatography-mass spectrometry in retinal lipid extracts from 8- to 9-week-old $A s a h 1^{+/+}$and $A s a h 1^{\mathrm{P} 361 \mathrm{R} / \mathrm{P} 361 \mathrm{R}}$ mice.

Analyses of the individual species of each sphingolipid class revealed an accumulation of many ceramide species by 3 to 4 weeks of age and all ceramide species studied in retinal samples from 8- to 9-week-old Asah1 ${ }^{\mathrm{P} 361 \mathrm{R} / \mathrm{P} 361 \mathrm{R}}$ mice (Figure 11, A and G). SM was unchanged in retinal samples from both 3- to 4- and 8- to 9-week-old Asah1 $1^{\mathrm{P} 361 \mathrm{R} / \mathrm{P} 361 \mathrm{R}}$ mice (Figure 11B). SM 18:0 was increased, and SM 24:0 was decreased, in retinal samples
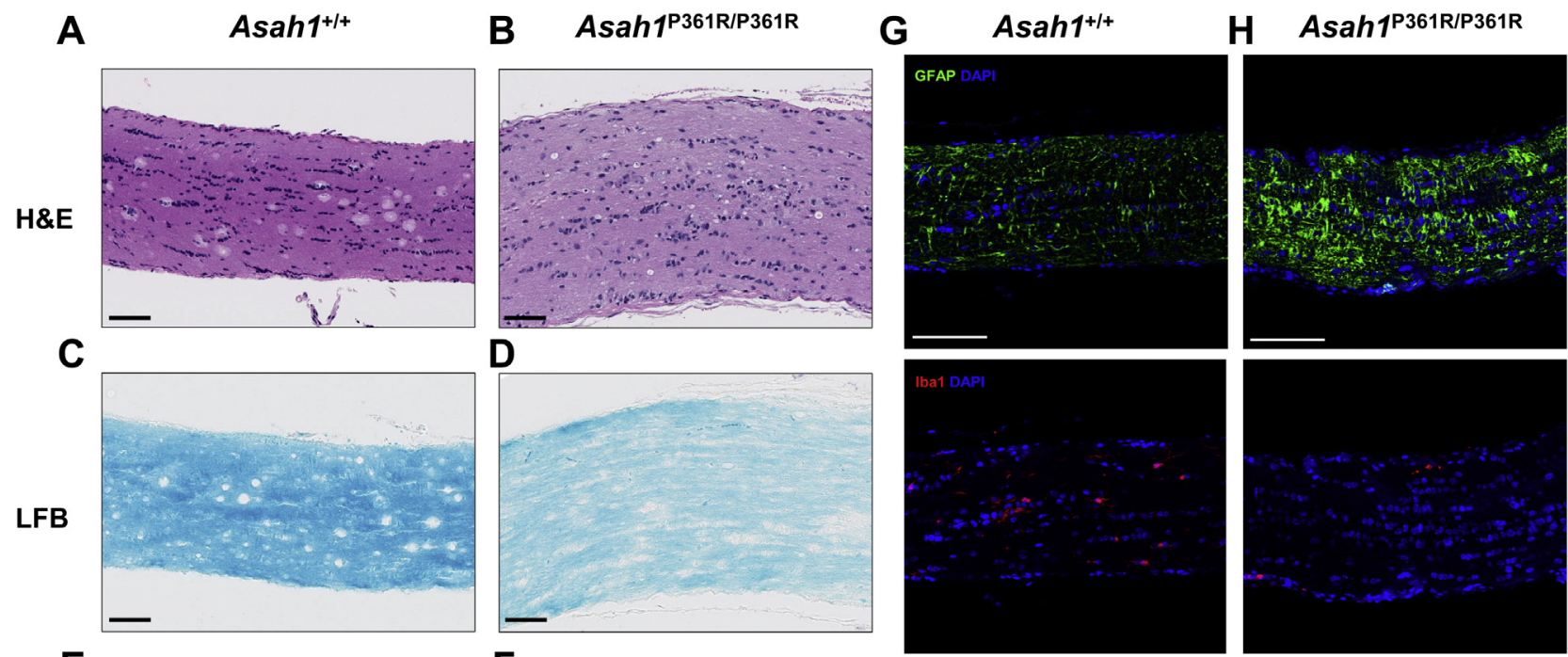

E

$\mathbf{F}$
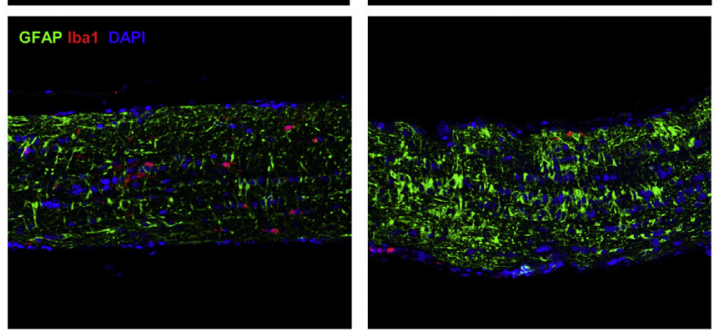

Figure 9 Optic nerve pathology in the Asah1 $1^{\mathrm{P} 361 \mathrm{R} / \mathrm{P} 361 \mathrm{R}}$ mice. A-F: Light micrograph of hematoxylin and eosin (H\&E), Luxol fast blue (LFB), and Mac-

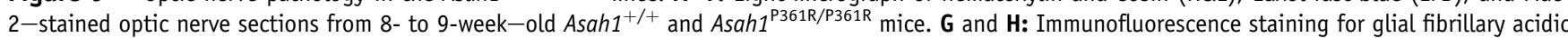
protein (GFAP), ionized calcium-binding adapter molecule 1 (Iba1), and DAPI on optic nerves of 8- to 9-week-old Asah1 $1^{+/+}$and Asah1 $1^{\mathrm{P} 361 \mathrm{R} / \mathrm{P} 361 \mathrm{R}}$ mice. Scale bars: $100 \mu \mathrm{m}(\mathbf{A}-\mathbf{F}) ; 50 \mu \mathrm{m}$ (G and $\mathbf{H})$. 

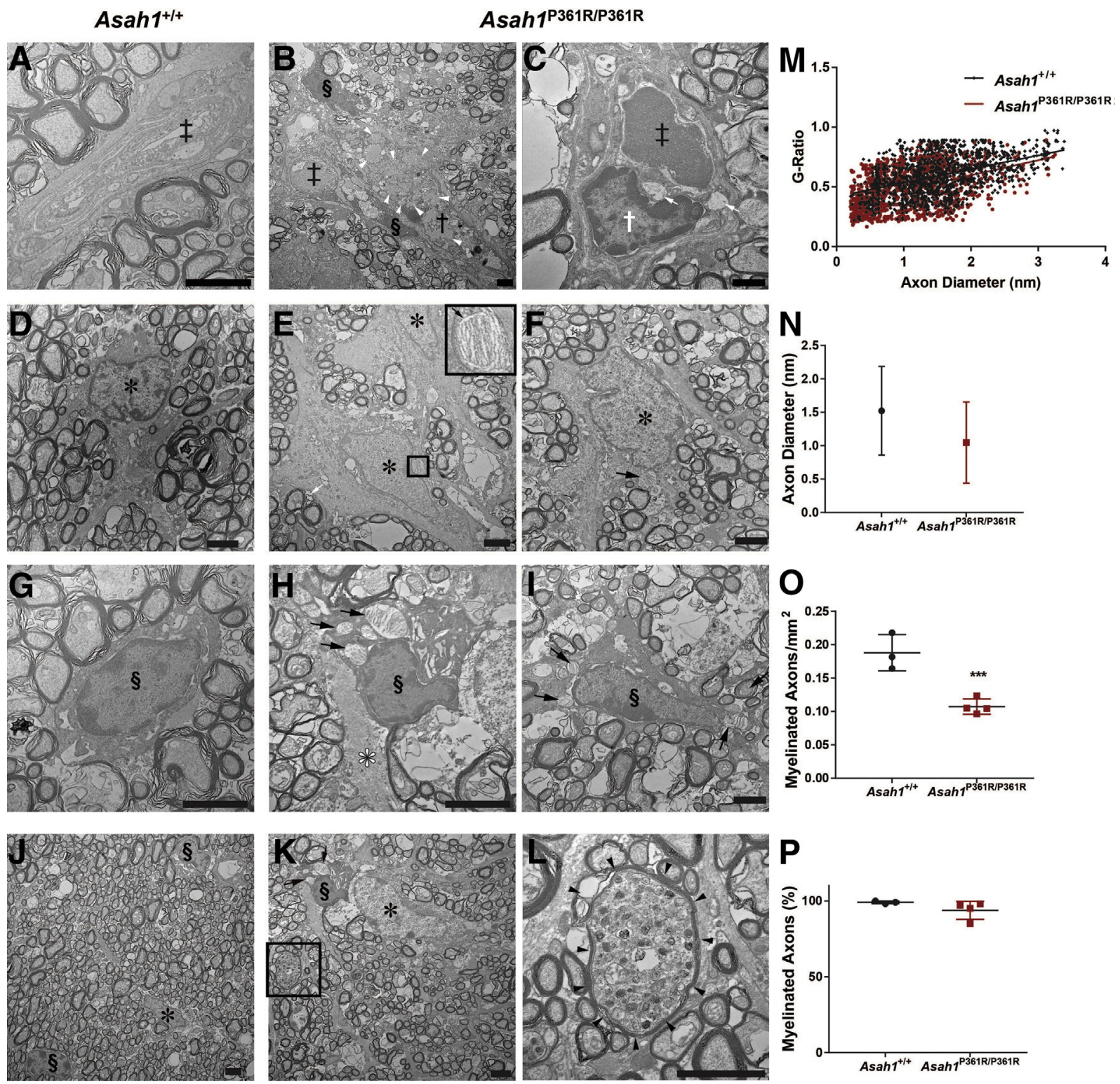

Figure 10 Optic nerve ultrastructure pathology in the $A s a h 1^{\mathrm{P} 361 \mathrm{R} / \mathrm{P} 361 \mathrm{R}}$ mice. A: Representative micrograph of a normal intraneuronal capillary in the Asah1 ${ }^{+/+}$mouse. B and C: Electron micrograph of endothelial cells and pericapillary macrophages with storage vacuoles in Asah1 $1^{\mathrm{P} 361 \mathrm{R} / \mathrm{P} 361 \mathrm{R}}$ mice. D: An astrocyte from an $\mathrm{Asah1}^{+/+}$mouse with finely structured cytoplasmic extensions. E and F: Hyperplastic astrocytes from Asah1 $1^{\mathrm{P} 361 \mathrm{R} / \mathrm{P} 361 \mathrm{R}}$ mice with zebra body-like and curved-linear tubular body CTB containing storage vacuoles. Boxed area in $\mathbf{E}$ is shown in higher magnification in the inset: Zebra body-like material is presented at higher magnification. G: Normal structured oligodendrocyte from an Asah1 $1^{+/+}$mouse. $\mathbf{H}$ and I: Oligodendrocytes containing zebra

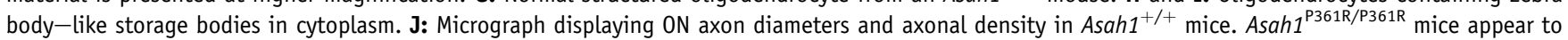
show less density in $\mathrm{ON}$ axons. $\mathbf{K}$ and L: Presence of neuronal axonal dystrophy (axonal spheroid) containing accumulated axonal cargo (K; highlighted by black boxed area and enlarged in $\mathbf{L}$ ). Double dagger denotes capillary lumina; white asterisk, astrocyte; black asterisk, astrocyte nucleus; white dagger, endothelial cell nucleus; black dagger, macrophage nucleus; section symbol, oligodendrocyte nucleus; black arrows, zebra body-like storage bodies; white arrow, storage vacuole with curvilinear tubular (Farber) bodies; white arrowheads, partly cleared macrophage storage vacuoles with curvilinear tubular (Farber) bodies; black arrowheads, outline of the axonal spheroid. The G-ratio (axon diameter/fiber diameter) was plotted against axon diameter. M: In samples from 8- to 9-week-old animals, Asah1 $1^{\mathrm{P} 361 \mathrm{R} / \mathrm{P} 361 \mathrm{R}}$ mice (1350 axons) show a difference in myelination compared with $A s a h 1^{+/+}$mice $(1333$ axons) $(P<0.001$ from clustered rank sum test). N: Comparison of axon diameters. $\mathbf{0}$ and P: Quantification of myelinated axon density and percentage of myelinated axons. $n=3(\mathbf{M}) .{ }^{* * *} P<0.001$. Scale bar $=2 \mu \mathrm{m}(\mathbf{A}-\mathbf{L})$.

from 8- to 9-week-old Asahl $1^{\mathrm{P} 361 \mathrm{R} / \mathrm{P} 361 \mathrm{R}}$ mice (Figure $11 \mathrm{H})$. Total MHC was elevated in retinal samples from both 3- to 4- and 8- to 9-week-old Asahl P361R/P361R $^{\text {Par }}$ mice (Figure 11, C and I). The C18:0 MHC species displayed the highest fold-change in retinal samples from both the 3- to 4- and 8- to 9-week-old Asahl ${ }^{\mathrm{P} 361 \mathrm{R} / \mathrm{P} 361 \mathrm{R}}$ mice (Figure 11, C and I). Sph levels were unchanged in retinal

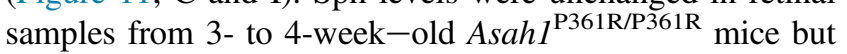
were significantly decreased in retinal samples from 8- to 9week-old Asahl $1^{\mathrm{P} 361 \mathrm{R} / \mathrm{P} 361 \mathrm{R}}$ mice (Supplemental Figure S9, 
$\mathrm{A}$ and $\mathrm{B})$. S1P was also measured in retinal samples from both age groups; however, readings were lower than the limit of detection (data not shown). Although C1P was not measured in retinal samples from the 3- to 4-week-old mice because of insufficient sample and lipid standards, no alterations in C1P levels were observed in retinal samples from 8- to 9-week-old Asahl $1^{\mathrm{P} 361 \mathrm{R} / \mathrm{P} 361 \mathrm{R}}$ mice (Supplemental Figure S9C).

Alterations in the relative abundance of sphingolipids were also detected in retinal samples from both the 3- to 4and 8- to 9-week-old AsahI ${ }^{+/+}$and AsahI $1^{\mathrm{P} 361 \mathrm{R} / \mathrm{P} 361 \mathrm{R}}$ mice. The relative abundance of C16:0 ceramide decreased, whereas the relative abundance of several other ceramides increased, in retinal samples from 3- to 4week-old Asahl ${ }^{\mathrm{P} 361 \mathrm{R} / \mathrm{P} 361 \mathrm{R}}$ mice (Figure 11D). The relative abundance of C16:0 ceramide also decreased in retinal

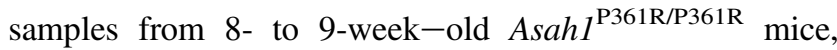

whereas the relative abundance of all of the other ceramides measured increased (Figure 11J). Although the relative abundance of SM was almost unchanged in retinal samples from 3- to 4-week-old Asahl ${ }^{+/+}$mice and 3- to 4-week-old Asahl $1^{\mathrm{P} 361 \mathrm{R} / \mathrm{P} 361 \mathrm{R}}$ mice (Figure 11E), an increase in the SM18:0 species and a slight decrease in many of the other SM species were observed in retinal samples from 8- to 9-week-old Asahl $1^{\mathrm{P} 361 \mathrm{R} / \mathrm{P} 361 \mathrm{R}}$ mice (Figure $11 \mathrm{~K}$ ). The largest change in MHC relative abundance was an increase in the C18:0 species, which coincided with decreased C16:0, C20:0, C24:1, and C24:0 species in retinal samples from both the 3- to 4- and the 8to 9-week-old Asahl ${ }^{\mathrm{P} 361 \mathrm{R} / \mathrm{P} 361 \mathrm{R}}$ mice (Figure 11, F and L). Because the quantification of sphingolipids in retinal samples from the 3- to 4- and 8- to 9-week-old mice was performed independently, no comparisons were made between the two age groups.

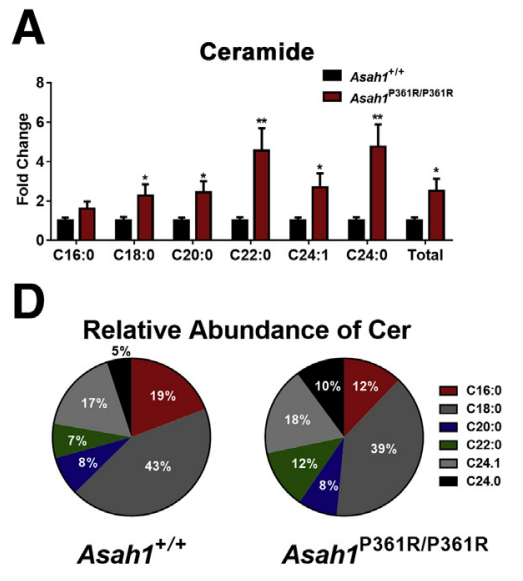

G

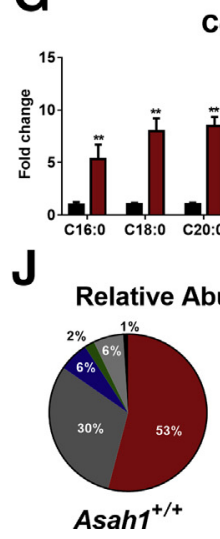

Ceramide

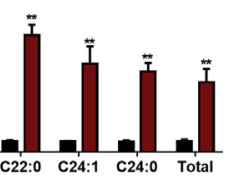

dance of Cer

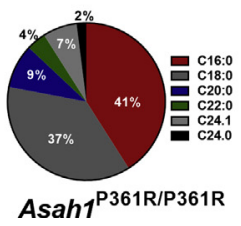

B

\section{3- to 4-Week-Old Mice}

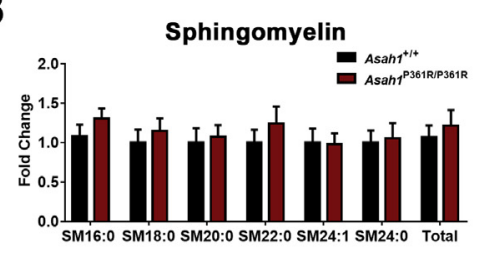

$\mathbf{E}$

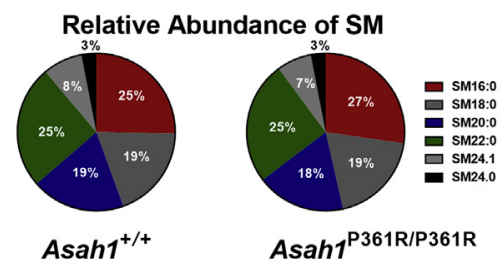

8- to 9-Week-Old Mice

H
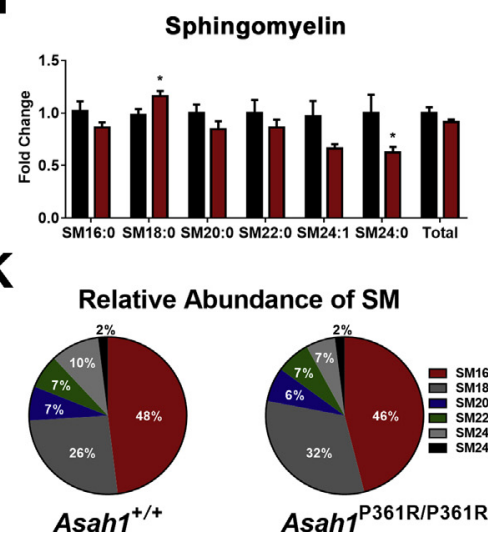

C

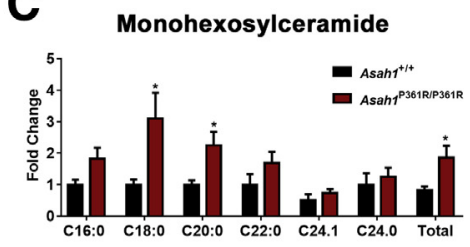

$\mathbf{F}$

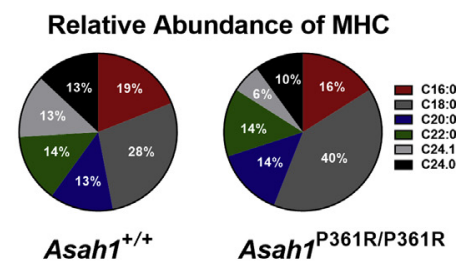

Figure 11 Altered sphingolipid species in the retina of $A s a h 1^{\mathrm{P} 361 \mathrm{R} / \mathrm{P} 361 \mathrm{R}}$ mice. Sphingolipids were quantified in retinal tissue from Asah1 ${ }^{+/+}$and Asah1 $1^{\mathrm{P} 361 \mathrm{R} / \mathrm{P} 361 \mathrm{R}}$ mice by liquid chromatography-mass spectrometry. Quantification of ceramide (Cer; A), sphingomyelin (SM; B), and monohexosylceramide

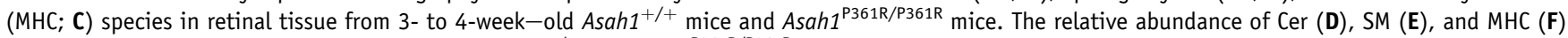
species in retinal tissue from 3- to 4-week-old $A s a h 1^{+/+}$and $A s a h 1^{\text {P361R/P361R }}$ mice. Quantification of Cer (G), SM (H), and MHC (I) Species in retinal tissue

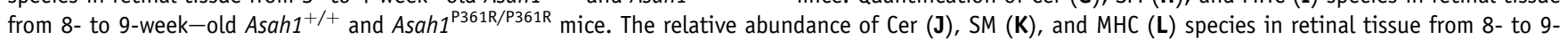
week-old $A s a h 1^{+/+}$and Asah1 ${ }^{\mathrm{P} 361 \mathrm{R} / \mathrm{P} 361 \mathrm{R}}$ mice. Data are expressed as means \pm SEM. $n=5$ to 6 animals for each genotype and age group. ${ }^{*} P<0.05$, $* * P<0.01$, and $* * * P<0.001$. 


\section{Discussion}

ACDase deficiency is an ultrarare orphan disease that can manifest along a wide broad clinical spectrum. The cardinal phenotypes include painful joints, formation of lipogranulomatous nodules, and aphonia. ${ }^{1}$ In classic and more severe variants, neurologic involvement is common and is often associated with functional and behavioral deficits. ${ }^{4,27}$ Ocular manifestations are commonly seen in patients who also display neurologic dysfunction, with the most common phenotype being a cherry red spot in the macula. ${ }^{3,9-12}$ Herein, we have provided an analysis of the ocular pathology present in the ACDase-deficient mouse. The results demonstrate that a deficiency in ACDase leads to a broad range of ophthalmic abnormalities. We highlight findings from noninvasive ocular imaging, characterize the affected cell types, and demonstrate visual impairment.

Although ocular disease is often present in FD, reports of an eye phenotype have thus far been restricted to superficial/ observational descriptions. In the literature, there are only two studies on the visual aspects of FD that were located. The first was published in 1966 and applied light microscopy and histologic techniques to reveal the presence of lipid granules within the RGCs of an FD patient who died at 11 months of age. ${ }^{9}$ The second report, published in 1985, described the retinal ultrastructure of an FD patient who died before the age of 3 years. ${ }^{28}$ Five types of cytoplasmic inclusions were identified in the second patient, with the most abundant being described as flattened stacks of osmophilic lamellae. ${ }^{28}$ The RGCs, glia, and phagocytic cells all showed significant inclusions. ${ }^{28}$ The findings from these reports are recapitulated in our murine model. The H\&E retinal tissue staining revealed a disorganized and vacuo-

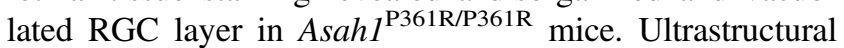
analyses of the retina also revealed significant storage pathology in various cell types - much like those reported by Zarbin and colleagues in $1985 .{ }^{28}$ Similar retinal pathology has also been noted in RGCs in other lysosomal storage disorders, such as Niemann-Pick disease type A, Pompe disease, and Tay-Sachs disease. ${ }^{29-31}$ Herein, significant storage pathology was further observed in endothelial cells, astrocytes, oligodendrocytes, and macrophage-like cells in the retina and optic nerves from $A s a h 1^{\mathrm{P} 361 \mathrm{R} / \mathrm{P} 361 \mathrm{R}}$ mice.

A heightened state of inflammation is characteristic of FD. An increased prevalence of inflammatory cells has been previously reported in the lungs, brain, and hematopoietic organs in this mouse model of FD..$^{21,22,32}$ Thus, finding that a deficiency in ACDase activity also leads to inflammation in the eye and optic nerve could be expected. Through the use of noninvasive ocular imaging, the formation of granulomas and nodules was noted in the anterior chambers. In addition, deposits close to the $\mathrm{ONH}$ of the fundus were seen with cSLO, and hyperreflectivity was noted along the $\mathrm{ONH}$ and vitreous body by OCT. These observations can be explained by the presence of inflammatory cells. IHC staining for Mac-2 and ultrastructure analyses further demonstrated a significant presence of abnormal macrophage morphologies primarily around the choroid and other vessels along the retina and optic nerve.

We previously reported increased vascular permeability in the Asahl ${ }^{\mathrm{P} 361 \mathrm{R} / \mathrm{P} 361 \mathrm{R}}$ mice. ${ }^{22}$ Although that study was primarily focused on lung pathology, one experiment involved a tail vein injection of Evans Blue Dye. Evans Blue Dye accumulation was measured in various organs in Asahl ${ }^{\mathrm{P} 361 \mathrm{R} / \mathrm{P} 361 \mathrm{R}}$ mice. ${ }^{22}$ Although not reported in that study, qualitatively, Asahl $1^{\mathrm{P361R} / \mathrm{P} 361 \mathrm{R}}$ mouse eyes were more intensely stained than controls. Inflammatory cytokines, such as monocyte chemoattractant proteins 1,3 , and 5 , increase in serum and organs from Asahl ${ }^{\mathrm{P} 361 \mathrm{R} / \mathrm{P} 361 \mathrm{R}}$ animals. ${ }^{22,26,33}$ Monocyte chemoattractant protein-1 also increases in the plasma of FD patients. ${ }^{33}$ Although cytokines were not measured in the retina, it is possible the combination of vascular leakage and altered cytokine production previously reported contributes to the macrophage and neutrophil recruitment described herein. ${ }^{22,26}$

The microglial and astroglial pathology was further characterized via Iba1 and GFAP immunofluorescence staining of retinal and optic nerve tissue. Asahl $1^{\mathrm{P} 361 \mathrm{R} / \mathrm{P} 361 \mathrm{R}}$ mice showed a progressive accumulation of GFAP in the retina and optic nerve, suggesting activation of astrocytes and Müller cells. Although significant macrophage infiltration was observed, Iba1 staining was largely unchanged, suggesting limited microglia involvement and that most infiltrated macrophages did not express Iba1..$^{21,26}$

Retinal dysplasia was also a prevalent feature in Asahl P361R/P361R mouse globes. Over $75 \%$ of globes analyzed had intermediate to severe retinal folding. Within the retinal folds, inflammatory cells were often discernible. Retinal folding was most prevalent in the regions near the $\mathrm{ONH}$. This may be because of the proximity of the central optic vein and artery, the region where increased macrophage infiltration was also observed. The phenotype seen in the eyes of $A s a h 1^{\mathrm{P} 361 \mathrm{R} / \mathrm{P} 361 \mathrm{R}}$ mice shares some similarities with the rodent models of experimental autoimmune uveoretinitis. ${ }^{34}$ During the early phase after experimental autoimmune uveoretinitis induction, cellular infiltrates can be observed in the vitreous and optic nerve head of mice eyes. ${ }^{35}$ As mice transition into the acute phase of experimental autoimmune uveoretinitis, inflammation is more severe, and retinal folding and edema might occur. ${ }^{36-38}$ Although edema within the retina was directly assessed, it may be occurring in the visual system of $A s a h 1^{\mathrm{P} 361 \mathrm{R} / \mathrm{P} 361 \mathrm{R}}$ mice. Specifically, hyperreflective deposits were observed from SLO imaging, and an increased retinal thickness and inflammation was seen in $A s a h 1^{\mathrm{P} 361 \mathrm{R} / \mathrm{P} 361 \mathrm{R}}$ mice, which is associated with edema. In addition, the lung and brain of $A s a h 1^{\mathrm{P} 361 \mathrm{R} / \mathrm{P} 361 \mathrm{R}}$ mice show signs of edema. ${ }^{21,22}$ Of interest, within the brain, approximately $70 \%$ of $A s a h 1^{\mathrm{P} 361 \mathrm{R} / \mathrm{P} 361 \mathrm{R}}$ mice at 9 weeks of age develop hydrocephalus. ${ }^{21}$ Although retinal pathology was not assessed previously, there may be a correlation between the 
development of hydrocephalus and retinal dysplasia because the retina is a part of the central nervous system.

The association between inflammation and retinal dysplasia has been reported in other models, such as cats infected with feline leukemia virus, dogs that were inoculated with canine herpes virus, and mice that were infected with Sindbis virus. ${ }^{39-41}$ The range of retinal dysplasia seen in the Asahl $1^{\mathrm{P} 361 \mathrm{R} / \mathrm{P} 361 \mathrm{R}}$ mice may be because of varying rates of inflammation between individuals.

Sphingolipid metabolites have been shown to regulate both the function and the trafficking of inflammatory cells. ${ }^{42}$ This has been shown in the eye, where cases of acute uveitis can change both lipid and sphingolipid profiles. ${ }^{43}$ Conversely, there is evidence demonstrating that sphingolipid metabolism can be altered because of inflammation. ${ }^{44-46}$ Direct intravitreal injection of bioactive sphingolipids, such as C8:0 in mice, can induce a dosedependent effect in recruiting inflammatory cells. ${ }^{47}$ From these studies, targeting the sphingolipid pathway has been suggested as an approach to treat uveitis. ${ }^{48}$ One of the most promising agents is FTY720 or fingolimod, an approved drug for the treatment of multiple sclerosis. FTY720 has shown significant anti-inflammatory effects in experimental autoimmune uveoretinitis rodent models. ${ }^{36,49,50}$ FTY720 is an analog of Sph that is derived from myriocin, a potent inhibitor of the de novo ceramide synthesis pathway. ${ }^{51}$ FTY720 is phosphorylated by sphingosine kinase- 2 in a similar manner to the modification of Sph to S1P. ${ }^{51}$ In addition to anti-inflammatory properties via S1P binding, FTY720 has also been shown to inhibit ceramide synthase, the class of enzyme that regulates ceramide acyl chain length during synthesis. ${ }^{52}$ Because of its anti-inflammatory effects, and potential decrease in ceramides, it is possible that treatment with FTY720 in conjunction with other antiinflammatory compounds may impede pathogenesis of FD.

We characterized the sphingolipid profiles of retinal lysates from 3- to 4- and 8- to 9-week-old Asahl ${ }^{\mathrm{P} 361 \mathrm{R} / \mathrm{P} 361 \mathrm{R}}$ mice. Ceramide accumulation is progressive and present as early as 3 to 4 weeks of age in the retina of Asahl ${ }^{\mathrm{P} 361 \mathrm{R} / \mathrm{P} 361 \mathrm{R}}$ mice. It is possible that this early accumulation of ceramide in the retinas of $A s a h l^{\mathrm{P} 361 \mathrm{R} / \mathrm{P} 361 \mathrm{R}}$ mice contributes to the abnormal ERG activity recorded in these animals. Retinal ceramide levels were significantly higher in the 8- to 9week-old Asahl $1^{\mathrm{P} 361 \mathrm{R} / \mathrm{P} 361 \mathrm{R}}$ mice. These older Asahl ${ }^{\mathrm{P} 361 \mathrm{R} /}$ P361R mice display progressive retinal inflammation, dysmorphic retinal pathology, and severe visual impairment. Thus, our data suggest that increasing retinal ceramide accumulation over time is associated with the retinal dysfunction and pathology reported herein.

The downstream metabolites of ceramide were measured, and it was found that only MHC was elevated in retinal lysate from $A s a h 1^{\mathrm{P} 361 \mathrm{R} / \mathrm{P} 361 \mathrm{R}}$ mice. SM was unchanged in both age groups of Asahl $1^{\mathrm{P} 361 \mathrm{R} / \mathrm{P} 361 \mathrm{R}}$ mice. Sph was unchanged in 3- to 4-week-old Asahl $1^{\mathrm{P} 361 \mathrm{R} / \mathrm{P} 361 \mathrm{R}}$ mice and decreased in 8- to 9-week-old Asahl $1^{\mathrm{P} 361 \mathrm{R} / \mathrm{P} 361 \mathrm{R}}$ mice. These findings appear specific to the retina because previous studies characterizing other organ systems in the ACDasedeficient mouse have noted accumulation of both ceramide and downstream ceramide metabolites. ${ }^{21,22,26}$ Within the liver and lungs of Asahl $1^{\mathrm{P} 361 \mathrm{R} / \mathrm{P} 361 \mathrm{R}}$ mice, SM, C1P, and MHC were significantly elevated. ${ }^{22,26}$ In the brain of Asahl ${ }^{\mathrm{P} 361 \mathrm{R} / \mathrm{P} 361 \mathrm{R}}$ mice, Sph and MHC were significantly elevated. ${ }^{21,26}$ Future in-depth studies that investigate upstream and downstream metabolites of ceramide at various time points in different cells and tissues from the ACDasedeficient mouse may provide further insight into the complex biochemistry of this disorder.

Maintaining sphingolipid equilibrium is essential for proper health and vision. Ocular manifestations are commonly reported in lysosomal storage disorders, and animal models have been instrumental in understanding disease progression. Studies on the acid sphingomyelinase-deficient mouse, the model for Niemann-Pick A/B disease, have revealed progressive retinal degeneration and inflammation. ${ }^{17,18}$ In the context of Sandhoff disease, work on the $\beta$-hexosaminidase mutant mouse showed robust storage pathology preferentially in the RGC and impaired neurite outgrowth from cultured retinal explants. ${ }^{16,53}$ Decreased ERG amplitude has also been documented in mice deficient in acid sphingomyelinase, hexosaminidase, and ceramide synthases 1,2 , and $4 .^{17,18,54}$ The similarities in disease manifestations seen in these reports and our current study suggest that insults to sphingolipid metabolism lead to comparable pathologies because homeostatic control of sphingolipids is tightly regulated.

Ceramide is a central signaling lipid in the sphingolipid pathway. In more common retinal diseases, such as retinitis pigmentosa, increases in ceramide can lead to downstream effects, such as photoreceptor cell death. ${ }^{55}$ One study in the retinal degeneration 10 mouse model showed that ceramides are increased with progressive photoreceptor degeneration and that treatment with the inhibitor myriocin could protect photoreceptors from apoptosis. ${ }^{56}$ Another study in a rat model of light-induced retinal degeneration showed a neuroprotective effect of FTY720 that acted independent of its immunosuppressive action. ${ }^{57}$ Together, these reports demonstrate the deleterious effects of ceramide in the retina. In the case of chronic ceramide accumulation, such as in $\mathrm{FD}$, alternative pathways may be switched on in response to sphingolipid buildup. Further work will be required to fully understand the role of ceramide signaling in FD and visual biology.

This study has provided the first in-depth analysis of the ocular manifestations and optic nerve pathology in the ACDase-deficient mouse. It has highlighted parallels between human cases and our model, particularly in terms of inflammation, storage pathology, and central nervous system decline. Given the lack of patients with FD and the dearth of available human tissue to study, this mouse model has aimed to fill the gap. Our results demonstrate a progressive decline in retinal function in Farber mice that coincides with severe retinal and optic nerve pathology and 
sphingolipid accumulation. These findings, although exploratory, may provide insight into the possible ocular pathology present in classic and severe variants of human FD.

Currently, there is an ongoing clinical trial (ID NCT03233841) to understand the natural history of FD. We have demonstrated the feasibility of noninvasive ocular imaging to assess and follow ocular pathology over time with serial testing in a mouse model of FD. Use of noninvasive ocular imaging may not only aid in diagnosis but serve as a screening modality to assess the inflammatory and neurologic status of patients with FD. In addition, recombinant enzyme therapy is currently being developed for the treatment of FD, and our laboratory has an ongoing interest in pursuing gene therapy to ameliorate this disorder. ${ }^{20,58,59}$ Noninvasive monitoring of the ocular conditions may also be a modality to assess the efficacy of these and future therapies.

\section{Acknowledgments}

We thank the staff at the Children's Hospital of Wisconsin Children's Research Institute Histology Core for technical assistance with histology and immunohistochemistry services; Christine Duris and Chris Skumatz for technical assistance; Dr. Suresh Kumar for microscopy assistance; and Dr. William M. Mckillop for critical review of the manuscript.

J.A.M. and F.P.S.Y. conceived and designed research; F.P.S.Y., B.S.S., J.S., A.E.S., M.S.N., J.G., I.S.K., and D.M.L. performed experiments; J.A.M., F.P.S.Y., B.S.S., J.S., A.E.S., M.S.N, and I.S.K. analyzed data; J.A.M, F.P.S.Y., J.S., I.S.K., D.M.L., and J.C. interpreted results; J.A.M. and F.P.S.Y. wrote the manuscript; J.A.M., F.P.S.Y., B.S.S., J.S., A.E.S., I.S.K., D.M.L., and J.C. edited and revised the manuscript; and J.A.M. and F.P.S.Y. approved the final version of the manuscript.

\section{Supplemental Data}

Supplemental material for this article can be found at https://doi.org/10.1016/j.ajpath.2018.10.018.

\section{References}

1. Levade T, Sandhoff K, Schulze H, Medin JA. Acid Ceramidase Deficiency: Farber Lipogranulomatosis. Scriver's OMMBID (Online Metabolic and Molecular Bases of Inherited Diseases). Edited by Valle D, Beaudet AL, Vogelstein B, Kinzler KW, Antonarakis SE, Ballabio A. New York, NY: McGraw-Hill, 2014

2. Schuchman EH: Acid ceramidase and the treatment of ceramide diseases: the expanding role of enzyme replacement therapy. Biochim Biophys Acta 2016, 1862:1459-1471

3. Zielonka M, Garbade SF, Kölker S, Hoffmann GF, Ries M: A crosssectional quantitative analysis of the natural history of Farber disease: an ultra-orphan condition with rheumatologic and neurological cardinal disease features. Genet Med 2017, 20:524-530
4. Ehlert K, Frosch M, Fehse N, Zander A, Roth J, Vormoor J: Farber disease: clinical presentation, pathogenesis and a new approach to treatment. Pediatr Rheumatol 2007, 5:15-22

5. Bao XH, Tian JM, Ji TY, Chang XZ: A case report of childhood Farber's disease and literature review. Zhonghua Er Ke Za Zhi 2017, 55:54-58

6. Arana L, Gangoiti P, Ouro A, Trueba M, Gómez-Muñoz A: Ceramide and ceramide 1-phosphate in health and disease. Lipids Health Dis 2010, 9:15

7. Chen H, Tran JA, Brush RS, Saadi A, Rahman AK, Yu M, Yasumura D, Matthes MT, Ahern K, Yang H: Ceramide signaling in retinal degeneration. Retin Degenerative Dis 2012, 723:553-558

8. Hannun YA, Obeid LM: Sphingolipids and their metabolism in physiology and disease. Nat Rev Mol Cell Biol 2017, 19:175-191

9. Cogan DG, Kuwabara T, Moser H, Hazard GW: Retinopathy in a case of Farber's lipogranulomatosis. Arch Ophthalmol 1966, 75:752-757

10. Moser HW, Prensky AL, Wolfe HJ, Rosman NP: Farber's lipogranulomatosis: report of a case and demonstration of an excess of free ceramide and ganglioside. Am J Med 1969, 47:869-890

11. Zarbin MA, Green WR, Moser AB, Tiffany C: Increased levels of ceramide in the retina of a patient with Farber's disease. Arch Ophthalmol 1988, 106:1163

12. Cvitanovic-Sojat L, Juraski RG, Sabourdy F, Fensom AH, Fumic K, Paschke E, Levade T: Farber lipogranulomatosis type 1-late presentation and early death in a Croatian boy with a novel homozygous ASAH1 mutation. Eur J Paediatr Neurol 2011, 15:171-173

13. Zetterström R: Disseminated lipogranulomatosis (Farber's disease). Acta Paediatr 1958, 47:501-510

14. Tanaka T, Takahashi K, Hakozaki H, Kimoto H, Suzuki Y: Farber's disease (disseminated lipogranulomatosis) a pathological, histochemical and ultrastructural study. Pathol Int 1979, 29:135-155

15. Chandwani R, Kuwar AS: Farber's disease. Indian Pediatr 2002, 39: 502

16. Sango K, Takano M, Ajiki K, Tokashiki A, Arai N, Kawano H, Horie H, Yamanaka S: Impaired neurite outgrowth in the retina of a murine model of Sandhoff disease. Invest Ophthalmol Vis Sci 2005, 46:3420-3425

17. Dannhausen K, Karlstetter M, Caramoy A, Volz C, Jägle H, Liebisch G, Utermöhlen O, Langmann T: Acid sphingomyelinase (aSMase) deficiency leads to abnormal microglia behavior and disturbed retinal function. Biochem Biophys Res Commun 2015, 464:434-440

18. Wu BX, Fan J, Boyer NP, Jenkins RW, Koutalos Y, Hannun YA, Crosson CE: Lack of acid sphingomyelinase induces age-related retinal degeneration. PLoS One 2015, 10:e0133032

19. Grishchuk Y, Stember KG, Matsunaga A, Olivares AM, Cruz NM, King VE, Humphrey DM, Wang SL, Muzikansky A, Betensky RA: Retinal dystrophy and optic nerve pathology in the mouse model of mucolipidosis IV. Am J Pathol 2016, 186:199-209

20. Alayoubi AM, Wang JC, Au BC, Carpentier S, Garcia V, Dworski S, El-Ghamrasni S, Kirouac KN, Exertier MJ, Xiong ZJ, Prive GG, Simonaro CM, Casas J, Fabrias G, Schuchman EH, Turner PV, Hakem R, Levade T, Medin JA: Systemic ceramide accumulation leads to severe and varied pathological consequences. EMBO Mol Med 2013, 5:827-842

21. Sikora J, Dworski S, Jones EE, Kamani MA, Micsenyi MC, Sawada T, Le Faouder P, Bertrand-Michel J, Dupuy A, Dunn CK, Yang Xuan Ingrid C, Casas J, Fabrias G, Hampson DR, Levade T, Drake Richard R, Medin JA, Walkley SU: Acid ceramidase deficiency in mice results in a broad range of central nervous system abnormalities. Am J Pathol 2017, 187:864-883

22. Yu FP, Islam D, Sikora J, Dworski S, Gurka' J, Lopez-Vasquez L, Liu M, Kuebler WM, Levade T, Zhang H, Medin JA: Chronic lung injury and impaired pulmonary function in a mouse model of acid ceramidase deficiency. Am J Physiol Lung Cell Mol Physiol 2017, 314:406-420

23. Dubra A, Harvey Z: Registration of $2 \mathrm{D}$ images from fast scanning ophthalmic instruments. Biomed Image Registration 2010, 6204: $60-71$ 
24. Chiu SJ, Li XT, Nicholas P, Toth CA, Izatt JA, Farsiu S: Automatic segmentation of seven retinal layers in SDOCT images congruent with expert manual segmentation. Opt Express 2010, 18:19413-19428

25. Fox MW: The visual cliff test for the study of visual depth perception in the mouse. Anim Behav 1965, 13:232-233

26. Yu FPS, Dworski S, Medin JA: Deletion of MCP-1 impedes pathogenesis of acid ceramidase deficiency. Sci Rep 2018, 8:1808

27. Eviatar L, Sklower SL, Wisniewski K, Feldman RS, Gochoco A: Farber lipogranulomatosis: an unusual presentation in a black child. Pediatr Neurol 1986, 2:371-374

28. Zarbin MA, Green WR, Moser HW, Morton SJ: Farber's disease: light and electron microscopic study of the eye. Arch Ophthalmol 1985, 103:73-80

29. Cogan DG, Kuwabara T: The sphingolipidoses and the eye. Arch Ophthalmol 1968, 79:437-452

30. Brownstein S, Carpenter S, Polomeno RC, Little JM: Sandhoff's disease ( $\mathrm{Gm} 2$ gangliosidosis type 2): histopathology and ultrastructure of the eye. Arch Ophthalmol 1980, 98:1089-1097

31. Yanovitch TL, Banugaria SG, Proia AD, Kishnani PS: Clinical and histologic ocular findings in pompe disease. J Pediatr Ophthalmol Strabismus 2010, 47:34-40

32. Dworski S, Berger A, Furlonger C, Moreau JM, Yoshimitsu M, Trentadue J, Au BC, Paige CJ, Medin JA: Markedly perturbed hematopoiesis in acid ceramidase deficient mice. Haematologica 2015, 100:162-165

33. Dworski S, Lu P, Khan A, Maranda B, Mitchell JJ, Parini R, Di Rocco M, Hugle B, Yoshimitsu M, Magnusson B, Makay B, Arslan N, Guelbert N, Ehlert K, Jarisch A, Gardner-Medwin J, Dagher R, Terreri MT, Marques Lorenco C, Barillas-Arias L, Tanpaiboon P, Solyom A, Norris JS, He X, Schuchman EH, Levade T, Medin JA: Acid ceramidase deficiency is characterized by a unique plasma cytokine and ceramide profile that is altered by therapy. Biochim Biophys Acta Mol Cell Biol Lipids 2017, 1863:386-394

34. Gasparin F, Takahashi BS, Scolari MR, Gasparin F, Pedral LS, Damico FM: Experimental models of autoimmune inflammatory ocular diseases. Arq Bras Oftalmol 2012, 75:143-147

35. Chen J, Qian H, Horai R, Chan C, Caspi RR: Use of optical coherence tomography and electroretinography to evaluate retinal pathology in a mouse model of autoimmune uveitis. PLoS One 2013, 8:e63904

36. Commodaro AG, Peron JPS, Lopes CT, Arslanian C, Belfort R, Rizzo LV Bueno V: Evaluation of experimental autoimmune uveitis in mice treated with FTY720. Invest Ophthalmol Vis Sci 2010, 51:2568-2574

37. Chan C, Caspi RR, Ni M, Leake WC, Wiggert B, Chader GJ, Nussenblatt RB: Pathology of experimental autoimmune uveoretinitis in mice. J Autoimmun 1990, 3:247-255

38. Caspi RR, Silver PB, Luger D, Tang J, Cortes LM, Pennesi G, Mattapallil MJ, Chan C: Mouse models of experimental autoimmune uveitis. Ophthalmic Res 2008, 40:169-174

39. Albert DM, Lahav M, Carmichael LE, Percy DH: Canine herpesinduced retinal dysplasia and associated ocular anomalies. Invest Ophthalmol Vis Sci 1976, 15:267-278

40. Albert DM, Lahav M, Colby ED, Shadduck JA, Sang DN: Retinal neoplasia and dysplasia, I: induction by feline leukemia virus. Invest Ophthalmol Vis Sci 1977, 16:325-337

41. Carreras B, Griffin DE, Silverstein AM: Sindbis virus-induced ocular immunopathology. Invest Ophthalmol Vis Sci 1982, 22:571-578

42. El Alwani M, Wu BX, Obeid LM, Hannun YA: Bioactive sphingolipids in the modulation of the inflammatory response. Pharmacol Ther 2006, 112:171-183
43. Wang H: Crosslink between lipids and uveitis: a lipidomic analysis. Invest Ophthalmol Vis Sci 2017, 58:5758

44. Rivera J, Proia RL, Olivera A: The alliance of sphingosine-1phosphate and its receptors in immunity. Nat Rev Immunol 2008, 8:753-763

45. Cyster JG, Schwab SR: Sphingosine-1-phosphate and lymphocyte egress from lymphoid organs. Annu Rev Immunol 2012, 30:69-94

46. Maceyka M, Spiegel S: Sphingolipid metabolites in inflammatory disease. Nat Rev Immunol 2014, 510:58-67

47. Chan AY, Chen R, Stone DS, Eckerd A, Mandal N: Bioactive sphingolipids as mediators of ocular inflammation: observations in an animal model. Invest Ophthalmol Vis Sci 2012, 53:1239

48. Copland DA, Liu J, Schewitz-Bowers LP, Brinkmann V, Anderson K, Nicholson LB, Dick AD: Therapeutic dosing of fingolimod (FTY720) prevents cell infiltration, rapidly suppresses ocular inflammation, and maintains the blood-ocular barrier. Am J Pathol 2012, 180:672-681

49. Kurose S, Ikeda E, Tokiwa M, Hikita N, Mochizuki M: Effects of FTY720, a novel immunosuppressant, on experimental autoimmune uveoretinitis in rats. Exp Eye Res 2000, 70:7-15

50. Raveney BJ, Copland DA, Nicholson LB, Dick AD: Fingolimod (FTY720) as an acute rescue therapy for intraocular inflammatory disease. Arch Ophthalmol 2008, 126:1390-1395

51. Chueh SJ, Kahan BD: Update on FTY720: review of mechanisms and clinical results. Curr Opin Organ Transplant 2003, 8:288-298

52. Berdyshev EV, Gorshkova I, Skobeleva A, Bittman R, Lu X, Dudek SM, Mirzapoiazova T, Garcia JG, Natarajan V: FTY720 inhibits ceramide synthases and up-regulates dihydrosphingosine 1phosphate formation in human lung endothelial cells. J Biol Chem 2009, 284:5467-5477

53. Denny CA, Alroy J, Pawlyk BS, Sandberg MA, D’Azzo A, Seyfried TN: Neurochemical, morphological, and neurophysiological abnormalities in retinas of Sandhoff and GM1 gangliosidosis mice. J Neurochem 2007, 101:1294-1302

54. Brüggen B, Kremser C, Bickert A, Ebel P, Dorp K, Schultz K, Dörmann P, Willecke K, Dedek K: Defective ceramide synthases in mice cause reduced amplitudes in electroretinograms and altered sphingolipid composition in retina and cornea. Eur J Neurosci 2016, 44:1700-1713

55. Sanvicens N, Cotter TG: Ceramide is the key mediator of oxidative stress-induced apoptosis in retinal photoreceptor cells. J Neurochem 2006, 98:1432-1444

56. Strettoi E, Gargini C, Novelli E, Sala G, Piano I, Gasco P, Ghidoni R: Inhibition of ceramide biosynthesis preserves photoreceptor structure and function in a mouse model of retinitis pigmentosa. Proc Nat Acad Sci U S A 2010, 107:18706-18711

57. Chen H, Tran JT, Eckerd A, Huynh TP, Elliott MH, Brush RS, Mandal NA: Inhibition of de novo ceramide biosynthesis by FTY720 protects rat retina from light-induced degeneration. J Lipid Res 2013 , $54: 1616-1629$

58. He X, Dworski S, Zhu C, DeAngelis V, Solyom A, Medin JA, Simonaro CM, Schuchman EH: Enzyme replacement therapy for Farber disease: proof-of-concept studies in cells and mice. BBA Clin 2017, 7:85-96

59. Ramsubir S, Nonaka $T$, Girbés CB, Carpentier S, Levade $T$, Medin JA: In vivo delivery of human acid ceramidase via cord blood transplantation and direct injection of lentivirus as novel treatment approaches for Farber disease. Mol Genet Metab 2008, 95:133-141 